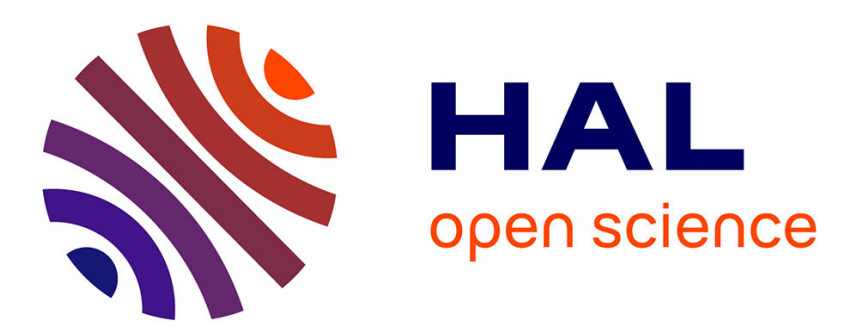

\title{
Efficient wavelength-tunable deep-diced ridge waveguide lasers in bulk $\mathrm{Yb3}+: \mathrm{CaF} 2$ crystal
}

Pavel Loiko, Ludovic Gauthier-Manuel, Gurvan Brasse, A. Braud, Abdelmjid Benayad, Patrice Camy

\section{- To cite this version:}

Pavel Loiko, Ludovic Gauthier-Manuel, Gurvan Brasse, A. Braud, Abdelmjid Benayad, et al.. Efficient wavelength-tunable deep-diced ridge waveguide lasers in bulk Yb3+:CaF2 crystal. Optical Materials, 2021, 113, pp.110861. 10.1016/j.optmat.2021.110861 . hal-03215596

\author{
HAL Id: hal-03215596 \\ https://hal.science/hal-03215596
}

Submitted on 7 Oct 2021

HAL is a multi-disciplinary open access archive for the deposit and dissemination of scientific research documents, whether they are published or not. The documents may come from teaching and research institutions in France or abroad, or from public or private research centers.
L'archive ouverte pluridisciplinaire HAL, est destinée au dépôt et à la diffusion de documents scientifiques de niveau recherche, publiés ou non, émanant des établissements d'enseignement et de recherche français ou étrangers, des laboratoires publics ou privés. 


\title{
Efficient wavelength-tunable deep-diced ridge waveguide lasers in bulk $\mathrm{Yb}^{3+}: \mathrm{CaF}_{2}$ crystal
}

\author{
Pavel Loiko $^{\mathrm{a}, 1}$, Ludovic Gauthier-Manuel ${ }^{\mathrm{b}, 1}$, Gurvan Brasse ${ }^{\mathrm{a}, 1}$, Alain Braud ${ }^{\mathrm{a}, 1}$, Abdelmjid Benayad ${ }^{\mathrm{a}, 1}$, \\ Patrice Camy a, 1 ,* \\ ${ }^{a}$ Centre de recherche sur les Ions, les Matériaux et la Photonique (CIMAP), UMR 6252 CEA-CNRS-ENSICAEN, Université de Caen, 6 Boulevard du Maréchal Juin, 14050, Caen, France \\ ${ }^{\mathrm{b}}$ FEMTO-ST Institute, 15B avenue des Montboucons, 25030, Besançon, Cedex, France
}

\section{A R T I C L E I N F O}

\section{Keywords}

Diamond saw dicing

Optical waveguides

Waveguide lasers

Calcium fluoride

Ytterbium ions

\begin{abstract}
A B S T R A C T
Channel (ridge) waveguides are produced in bulk 4.5 at. $\% \mathrm{Yb}^{3+}: \mathrm{CaF}_{2}$ crystals by "deep" diamond saw dicing. They possess a rectangular profile with high aspect ratio (a width of 10-50 $\mu \mathrm{m}$ and a depth of $200 \mu \mathrm{m}$ ) and good verticality. The r.m.s. surface roughness of the diced side walls is only $0.5 \mathrm{~nm}$. The waveguide propagation losses are as low as $0.13 \pm 0.05 \mathrm{~dB} / \mathrm{cm}$ at $\sim 1 \mu \mathrm{m}$ (for the $40 \mu \mathrm{m}$ wide waveguide and TM-polarization) and they slightly increase for narrower structures. A continuous-wave $\mathrm{Yb}^{3+}: \mathrm{CaF}_{2}$ waveguide laser generated a maximum output power of $723 \mathrm{~mW}$ at $1029-1051 \mathrm{~nm}$ with a slope efficiency $\eta$ of $76.0 \%$ ( $\nu \mathrm{s}$. the absorbed pump power), a laser threshold of $165 \mathrm{~mW}$, and slightly multimode laser output $\left(\mathrm{M}_{\mathrm{x}}^{2}=1.05, \mathrm{M}_{\mathrm{y}}^{2}=1.3\right)$. The waveguides exhibited lower propagation losses and better laser performance for TM polarized pump (as compared to TE polarized one). The laser emission was partially polarized. The waveguide laser allowed for continuous wavelength tuning between 1009 and $1072 \mathrm{~nm}$ (tuning range: $63 \mathrm{~nm}$ ). The developed waveguides are promising for compact and integrated mode-locked sources at $\sim 1 \mu \mathrm{m}$.
\end{abstract}

\section{Introduction}

In integrated optics, dicing is a process by which a die (a functional block of material) is separated from the wafer. One of the most common ways of dicing is mechanical sawing using a machine called a dicing saw. Such a machine uses a high rotation speed extremely thin diamond blade and produces cuts with high surface quality and well-controlled geometry. This technology was mainly applied to semiconductor wafers (e.g., $\mathrm{Si}$ or GaAs). In the recent years, there is a raising interest for application of this technology to micro-structuring of optical materials. One attractive application here is the fabrication of optical waveguides (WGs) $[1,2]$. The advantages of diamond saw dicing for waveguide fabrication are the following: (i) well-controlled geometrical shape with $\mu \mathrm{m}$-scale precision [1], (ii) small surface roughness of cuts [3] and, thus, low scattering losses and high optical quality of the surfaces [4], (iii) the availability of commercially available dicing saws and (iv) the variety of suitable materials such as thin films [5], polymers [6], glasses [7] and single-crystals $[1,2]$.
By diamond saw dicing of laser-active materials, one can produce active WGs for laser emission [8-12]. Such WGs having a well-defined transverse geometrical profile are classified as surface channel (ridge) ones. Surface WGs are of interest for bio- and environmental sensing applications as the intracavity mode can interact with the surrounding material (e.g., gas, liquid or deposited film) via evanescent-field coupling $[13,14]$.

So far, laser-active surface WGs were produced by diamond-saw dicing in different materials. The general feature of these studied is that before the dicing, a waveguiding layer of material was formed (e.g., by liquid phase epitaxy (LPE) [10], pulsed laser deposition (PLD) [9], swift heavy ion irradiation [8], ion in-diffusion [11] etc.), so that the dicing was used to change the laser geometry from planar to channel waveguide one. Waeselmann et al. patterned $\mathrm{Nd}^{3+}: \alpha-\mathrm{Al}_{2} \mathrm{O}_{3}$ (sapphire) thin films deposited by PLD; the channel waveguide laser with a cross-section of $41(x) \times 2.6(y) \mu \mathrm{m}^{2}$ generated $322 \mathrm{~mW}$ at $\sim 1.09 \mu \mathrm{m}$ with a slope efficiency of $\sim 12 \%$ corresponding to relatively high propagation losses of $\sim 6 \mathrm{~dB} / \mathrm{cm}$ [9]. Recently, Loiko et al. fabricated square $30(x) \times 30(y) \mu \mathrm{m}^{2}$ waveguides in $\mathrm{Tm}^{3+}: \mathrm{LiYF}_{4} \mathrm{LPE}$ films yielding much

\footnotetext{
* Corresponding author.

E-mail address: patrice.camy@ensicaen.fr (P. Camy)

1 The Authors contributed equally to the manuscript.
} 
better power transfer characteristics (an output power of $1.30 \mathrm{~W}$ at $1.88 \mu \mathrm{m}$ with a slope efficiency of $80 \%$ ) and lower propagation losses $(0.28 \mathrm{~dB} / \mathrm{cm})[10]$.

Another approach is to apply dicing to microstructuring of bulk crystals with a goal of fabricating surface WGs with high aspect ratios (depth/width, or $y / x$ ). This approach was referred as deep diamond saw dicing resulting in nearly inverted planar waveguide geometry. It was first applied to surface micro-structuring of bulk nonlinear crystals: Courjal et al. fabricated ridges in $\mathrm{LiNbO}_{3}$ with high aspect ratios up to $y / x=500\left(1(x) \times 500(y) \mu \mathrm{m}^{2}\right)$, good side-wall verticality and propagation losses down to $0.5 \mathrm{~dB} / \mathrm{cm}$ (for a $6(x) \times 35(y) \mu \mathrm{m}^{2}$ waveguide) [1]. Very recently, we applied this approach to bulk laser crystals using $\mathrm{Tm}^{3+}: \mathrm{LiYF}_{4}$ as a reference material [15]. Despite the relatively low propagation losses $(0.1-0.4 \mathrm{~dB} / \mathrm{cm}$, depending on the aspect ratio), the laser performance of such WGs was affected by thermal effects (the laser operated in quasi-continuous-wave regime). Moreover, the localization of the laser mode was not fully clarified.

Among the laser host materials suitable for power-scalable applications, cubic calcium fluoride $\left(\mathrm{CaF}_{2}\right)$ is attracting a lot of attention [16]. From the point of view of thermo-mechanical properties, it provides high thermal conductivity $\left(\sim 9.7 \mathrm{~W} \mathrm{~m}^{-1} \mathrm{~K}^{-1}\right)$ [17], isotropic thermal expansion and weak and negative thermal lensing [16]. $\mathrm{CaF}_{2}$ can be easily doped with rare-earth ions such as trivalent ytterbium $\left(\mathrm{Yb}^{3+}\right)$ and it features strong ion clustering already at low doping levels ( $>0.1$ at.\%) leading to significant inhomogeneous broadening of spectral bands (a glassy-like behavior) [18]. The latter is attractive for broadband wavelength tuning $[19,20]$ and especially generation [21] and amplification [22] of ultrashort pulses, including high-power laser facilities [23]. Thus, $\mathrm{Yb}^{3+}: \mathrm{CaF}_{2}$ crystals appear as excellent candidates for power-scalable waveguide lasers.

In the present work, we aimed to demonstrate first deep diamond saw diced active WGs in bulk $\mathrm{Yb}^{3+}: \mathrm{CaF}_{2}$ exhibiting highly-efficient and wavelength-tunable laser emission.

To date, there are very few reports on ytterbium calcium fluoride WGs. Petit et al. reported on fabrication of planar and ridge WGs in bulk $\mathrm{Yb}^{3+}: \mathrm{CaF}_{2}$ by $\mathrm{H}^{+}$ion implantation without laser action [24]. Ren et al. fabricated buried channel WGs in bulk $\mathrm{Yb}^{3+}, \mathrm{Na}^{+}: \mathrm{CaF}_{2}$ by ultrafast laser inscription (ULI) and achieved $174 \mathrm{~mW}$ at $\sim 1.01 \mu \mathrm{m}$ with an optical-to-optical efficiency of 45.3\% [25]. Molecular beam epitaxy (MBE) [26] and LPE [27] growth of $\mathrm{Yb}^{3+}$-doped $\mathrm{CaF}_{2}$ films was reported and laser operation in planar waveguide geometry was achieved: Loiko et al. obtained $114 \mathrm{~mW}$ at $1.04 \mathrm{~nm}$ with a slope efficiency of $12.9 \%$ [28]. However, these studies have not fully exploited the power scaling capabilities of calcium fluoride and intrinsically high slope efficiencies of $\mathrm{Yb}^{3+}$ laser scheme based on resonant pumping.

\section{Fabrication and characterization of waveguides}

\subsection{Crystal growth}

As a laser gain material, we used bulk ytterbium-doped calcium fluoride $\left(\mathrm{Yb}^{3+}: \mathrm{CaF}_{2}\right)$ crystal. The 4.5 at. $\% \mathrm{Yb}^{3+}: \mathrm{CaF}_{2}$ crystal (in the crystal, $\mathrm{Yb}^{3+}$ ion density: $N_{\mathrm{Yb}}=11.03 \times 10^{20} \mathrm{~cm}^{-3}$ ) was grown using a conventional Bridgman technique with a homemade furnace. A mixture of high purity ( $4 \mathrm{~N}$ ) $\mathrm{CaF}_{2}$ and $\mathrm{YbF}_{3}$ powders was introduced into a graphite crucible. A good vacuum $\left(<10^{-5}\right.$ mbar) was realized before refilling the growth chamber with a mixture of $\mathrm{Ar}$ and $\mathrm{CF}_{4}$ gases to avoid the formation of oxyfluoride phase. The furnace temperature was set to about $50 \mathrm{~K}$ higher than the melting point of $\mathrm{CaF}_{2}$. After soaking, the charge was thoroughly melted, and the crystal growth was carried out with a rate of $2-4 \mathrm{~mm} / \mathrm{h}$. When the growth was completed, the crystal was cooled down to room temperature (RT, $293 \mathrm{~K}$ ) within $48 \mathrm{~h}$.

\subsection{Deep diamond saw dicing}

For diamond saw dicing, a rectangular sample was cut from the $\mathrm{Yb}^{3+}: \mathrm{CaF}_{2}$ crystal. It was oriented for light propagation along the [111] crystallographic direction employing a Laue diffractometer. The sample thickness $t$ was $6.0 \mathrm{~mm}$. The input and output surfaces, as well as the top surface of the sample were polished to laser quality with good parallelism. They remained uncoated.

The top surface of the sample was subjected to precision diamond saw dicing. For processing calcium fluoride, we developed a specific process to ensure good surface quality and minimize the stresses by reducing revolution speeds of the blades and diamond sizes. These parameters were optimized in a set of test experiments to avoid edge chipping. We have also developed a calibration process to control the ridge geometry and thickness. The selected dicing parameters ensured gentle polishing of the ridge side walls leading to their small roughness. The dicing depth was $200 \mu \mathrm{m}$ and the ridges with the widths of $10-50 \mu \mathrm{m}$ (with a step of $10 \mu \mathrm{m}$ ) were produced, resulting in the aspect ratios $y / x$ in the range 4-20. The ridges were separated by a distance of $500 \mu \mathrm{m}$. No additional polishing was applied to the input and output facets of the sample.

\subsection{Confocal microscopy}

The geometry and surface morphology of the fabricated WGs were studied using a confocal laser microscope (Sensofar S-neox) equipped with a set of microscope objectives $(10 \times, 20 \times$ and $100 \times)$ and a blue light-emitting diode (LED, $\lambda=405 \mathrm{~nm}$ ). It operated in the bright-field regime and reflection mode.

First, we observed one of the end-facets with different magnifications, Fig. 1(a-d). In Fig. 1(a), one can see several ridges of different width $(10,20$ and $30 \mu \mathrm{m})$, as well as part of the top sample surface which remained undiced. There are no cracks propagating in the bulk crystal volume (the dark lines are due to small surface imperfections originating from the polishing process; they are highlighted because of the reflection mode of observation which is very sensitive to the surface quality). In Fig. 1(b), one ridge with an intermediate width $(30 \mu \mathrm{m})$ is shown. One can see that there is no chipping of the end-facet which may appear when the revolution speed of the blade is too high. In Fig. 1 (c), we observed the upper part of the same ridge having almost perfect rectangular profile with vertical side walls. However, in the bottom part of the waveguide, Fig. 1(d), a certain rounding is observed. It is slightly asymmetric at two opposite side walls. This shape is typical for diamond saw dicing, as the blade quality slowly decreases with time resulting in rounded bottom. No $\mu \mathrm{m}$-range dicing debris are observed (some sub- $\mu \mathrm{m}$-sized particles are visualized as bright points in Fig. 1(c and d)).

Furthermore, we observed the top surface of the sample near one of the end-facets, see Fig. 1(d). The WGs have a straight geometry with no cracks nor chipping along all their length. The ridges propagated through the entire length of the sample. A close view on one of the WGs is shown in Fig. 1(e). When observing the sample from the top, the rectangular ridge geometry is well confirmed.

To conclude about the roughness of different surfaces of fabricated ridges, we employed the confocal mode. For this, the ridge with a width of $40 \mu \mathrm{m}$ was used. First, we looked at the top surface of the ridge, Fig. 2(a). Its quality is determined by polishing prior to the dicing process. The root mean square (r.m.s.) roughness of this surface in the longitudinal direction (along the waveguide) is $1.2 \mathrm{~nm}$, Fig. 3(a).

Then, we observed one of the side walls (its surface quality is determined by soft polishing during the dicing process), Fig. 2(b). The corresponding r.m.s. roughness along the waveguide is even further decreased with respect to the top surface, down to $0.5 \mathrm{~nm}$, Fig. 3(b). This 

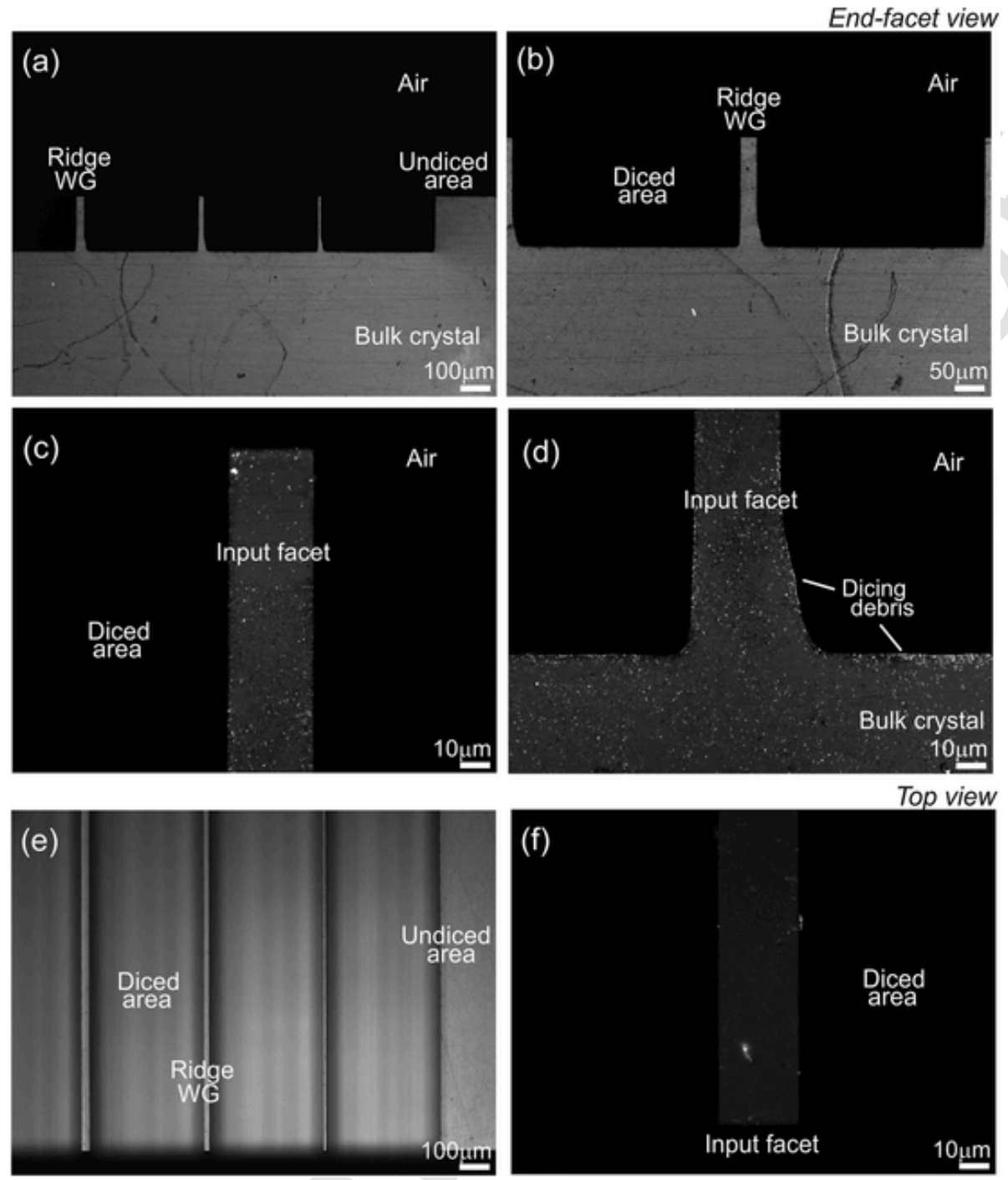

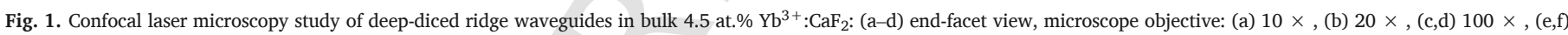
top view, microscope objective: (e) $10 \times$, (f) $100 \times$. Bright field, reflection mode, $\lambda=405 \mathrm{~nm}$.

indicates the role of dicing in maintaining the good quality of the side walls which is relevant for reducing the waveguide propagation losses. Another possibility to observe the same surface is along the vertical direction. Within upper $3 / 4(150 \mu \mathrm{m})$ of the ridge height, very good verticality is preserved, as the maximum deviation does not exceed $15 \mathrm{~nm}$, Fig. 3(c). In the lower part (1/4) of the ridge, the above mentioned rounding appears.

We have also observed the diced (bottom) area between two adjacent WGs, Fig. 2(c). It has a characteristic lined morphology with the direction of lines being parallel to the dicing direction. While the r.m.s. surface roughness studied across these lines, Fig. 3(d), is increased to $40 \mathrm{~nm}$, it is still relatively low. Note that the guided light does not interact with this surface.

Finally, we have observed one of the end-facets of the waveguide, Fig. 2(d). Its quality is again determined by pre-polishing before the dicing process. The corresponding roughness plot is shown in Fig. 3(e) corresponding to a r.m.s. devitation of $4.5 \mathrm{~nm}$. In addition, a certain rounding (variation of roughness up to $20 \mathrm{~nm}$ ) was observed near the top surface of the ridge and it originates from the polishing of the bulk crystal. As expected, Fig. 2(d) also reveals the above mentioned asymmetry of the waveguide base which is characteristic of the dicing process.

\subsection{Waveguiding properties}

For studying the waveguiding properties and optical losses of the fabricated WGs, we used a CW Ti:Sapphire laser (3900 S, Spectra Physics) emitting in the fundamental mode $\left(\mathrm{TEM}_{00}, \mathrm{M}^{2} \approx 1\right)$ with a linear polarization. Its output was coupled into the WGs using a spherical uncoated $\mathrm{CaF}_{2}$ lens (focal length, $\mathrm{f}=40 \mathrm{~mm}$ ) resulting in a pump spot $2 w_{\mathrm{P}}$ of $27 \pm 5 \mu \mathrm{m}$. The transmitted light was collimated using another spherical $\mathrm{CaF}_{2}$ lens ( $\mathrm{f}=15 \mathrm{~mm}$ ) and the profile of the guided mode at the output facet was captured using a CCD camera (BladeCam-XHR, DataRay Inc.). The scale calibration was performed by illuminating the WGs with known dimensions using a near-IR light source (LED) placed before the focusing lens.

The near-field profiles of the guided pump modes at the wavelength of $\lambda_{\mathrm{p}}=979.5 \mathrm{~nm}$ are shown in Fig. 4. This study was performed for the vertical laser polarization. The coupled light is well confined within the ridges with almost negligible leakage into the bulk crystal volume. The pump mode is clearly multimode for all the WGs: for the $50 \mu \mathrm{m}$ wide ridge, it is $\mathrm{TM}_{23}$ and for the $10 \mu \mathrm{m}$ one, it is $\mathrm{TM}_{01}$. There is a small asymmetry of the mode in the bottom part of the waveguide which matches the rounding revealed using the confocal microscopy. 


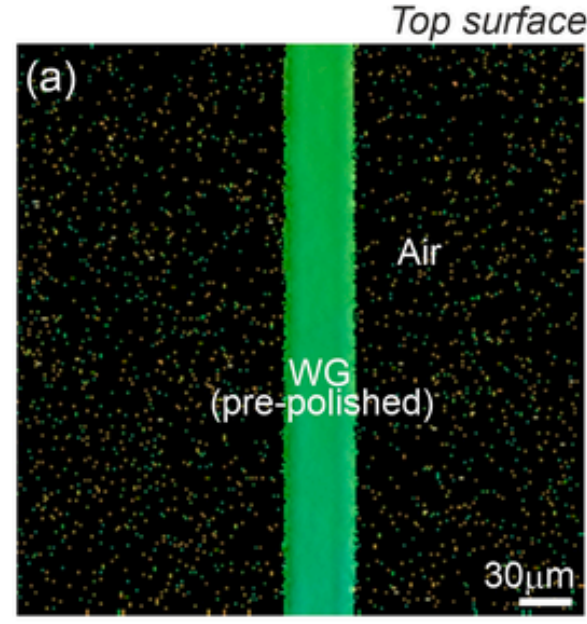

Diced area

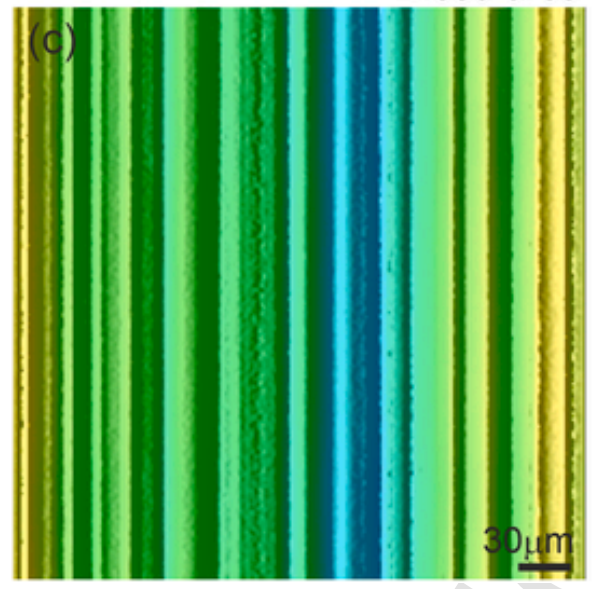

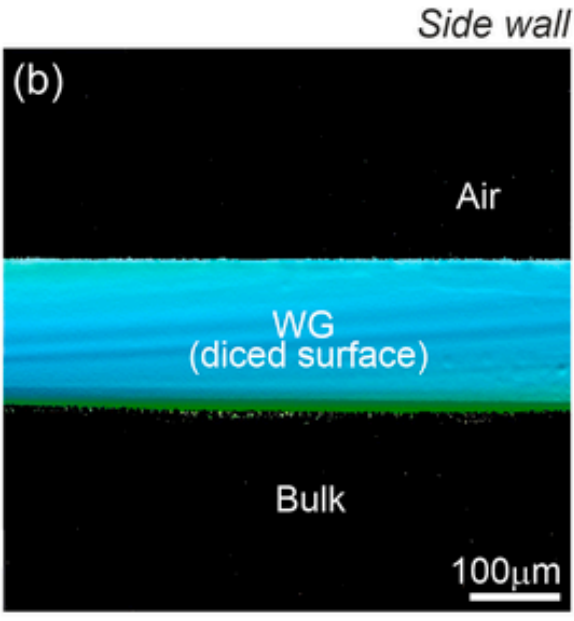

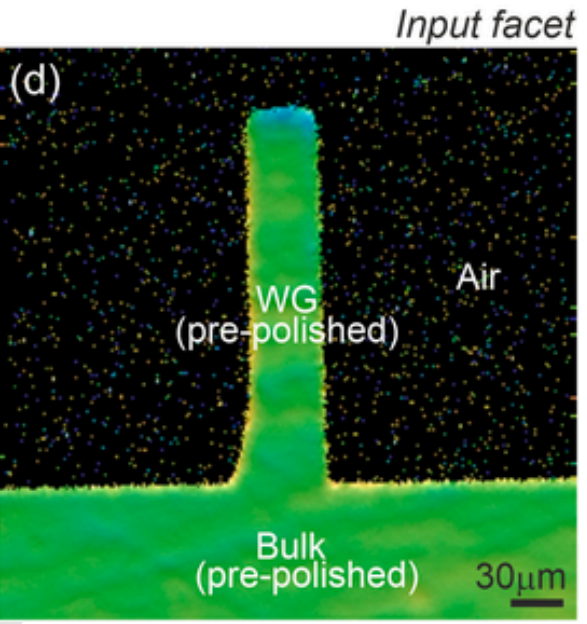

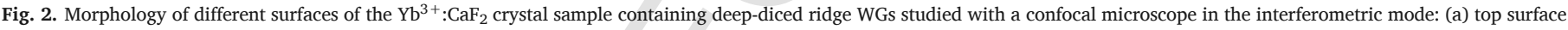
of the guide (pre-polished); (b) one of the waveguide side walls (diced); (c) diced area between two adjacent guides; (d) input facet (pre-polished). WG width: $40 \mu \mathrm{m}$.

For the performed experiment, the Rayleigh length for the laser beam in the crystal $z_{\mathrm{R}}=\left(\pi w_{\mathrm{P}}^{2} n\right) /\left(\lambda_{\mathrm{p}} \mathrm{M}^{2}\right)$ is $0.84 \mathrm{~mm}$, so that in the conditions of free propagation, the beam diameter at the output facet of the sample would be $2 \mathrm{w} \sim 200 \mu \mathrm{m}$ (along the vertical direction), i.e., filling the whole volume of the ridge.

To study the waveguide propagation losses, the Ti:Sapphire laser was tuned out of the main absorption peak of $\mathrm{Yb}^{3+}$ ions, to $\lambda_{\mathrm{p}}=912.0 \mathrm{~nm}$. The intensity of the scattered pump along the waveguide was observed from its top surface using a CCD-camera and a microscope objective, as shown in Fig. 5. The experiments were performed for two pump polarizations, vertical and horizontal. The incident power was set to be very low $(<5 \mathrm{~mW})$ to avoid absorption saturation, i.e., the experiment was performed in the small-signal regime. The on-axis intensity of the pump radiation was fitted using the formula $I(z)=I_{0} \times \exp \left(-\delta_{\text {tot }} z\right)$, where $I_{0}$ is the intensity near the input facet of the waveguide, $\delta_{\text {tot }}=\alpha_{\text {abs }}+\delta_{\text {loss }}$ is the total loss coefficient, $\alpha_{\mathrm{abs}}=\sigma_{\mathrm{abs}}^{\mathrm{P}} N_{\mathrm{Yb}}=1.07 \mathrm{~cm}^{-1}$ is the small-signal absorption coefficient at the pump wavelength, where $\sigma_{\text {abs }}^{\mathrm{P}}=0.97 \times 10^{-21} \mathrm{~cm}^{2}, \delta_{\text {loss }}$ is the coefficient of passive losses and $z$ is the axial coordinate. The best-fits are shown in Fig. 5 and the obtained $\delta_{\text {loss }}$ values expressed in $\mathrm{dB} / \mathrm{cm}$ are summarized in Table 1 .

The propagation losses tend to increase for narrower WGs for both laser polarizations, e.g., from $0.17 \mathrm{~dB} / \mathrm{cm}$ for $50 \mu \mathrm{m}$ wide waveguide up to $0.52 \mathrm{~dB} / \mathrm{cm}$ for the $10 \mu \mathrm{m}$ wide one (for the vertical polarization). We assign this to two reasons: (i) stronger mode overlap with the side walls for smaller WGs and (ii) higher surface roughness and worse parallelism for the side walls of the smaller WGs. The latter effect can originate from stronger vibrations of the blade which is in contact with smaller volume of the material. Second, the propagation losses are almost two times higher for horizontally polarized light, e.g., $\delta_{\text {loss }}=0.34 \mathrm{~dB} / \mathrm{cm}$ for the $50 \mu \mathrm{m}$ wide waveguide and $0.91 \mathrm{~dB} / \mathrm{cm}$ for the $10 \mu \mathrm{m}$ one. Note that cubic calcium fluoride is an optically isotropic material. The observed polarization anisotropy of scattering losses for guided light may originate from the dicing process itself as it creates slightly asymmetric ridge profile.

The pump coupling efficiency $\eta_{\text {coupl }}=P_{\text {coupl }} / P_{\text {inc }}$ was determined in a separate set of experiments at $892.0 \mathrm{~nm}$ (out of the $\mathrm{Yb}^{3+}$ absorption) by monitoring the power at the output facet of the waveguide. As expected from the geometrical overlap of the pump beam and the waveguide cross-section, $\eta_{\text {coupl }}$ decreased for smaller widths of the WGs, from $77.9 \%$ for the $50 \mu \mathrm{m}$ wide waveguide down to $43.0 \%$ for the $10 \mu \mathrm{m}$ wide one. Note that these values include Fresnel loss at the uncoated input facet of the ridge $\left(T_{\mathrm{Fr}}=96.1 \%\right.$, calculated using the refractive index $n=1.4927$ [29]).

\section{Laser operation}

\subsection{Laser set-up}

The scheme of the laser set-up is shown in Fig. 6(a). The $\mathrm{Yb}^{3+}: \mathrm{CaF}_{2}$ crystalline sample with the diced WGs was mounted on a passively-cooled Cu-holder using a silver paint to improve the heat dissipation. The sample was placed in a linear plano-plano cavity formed by a 

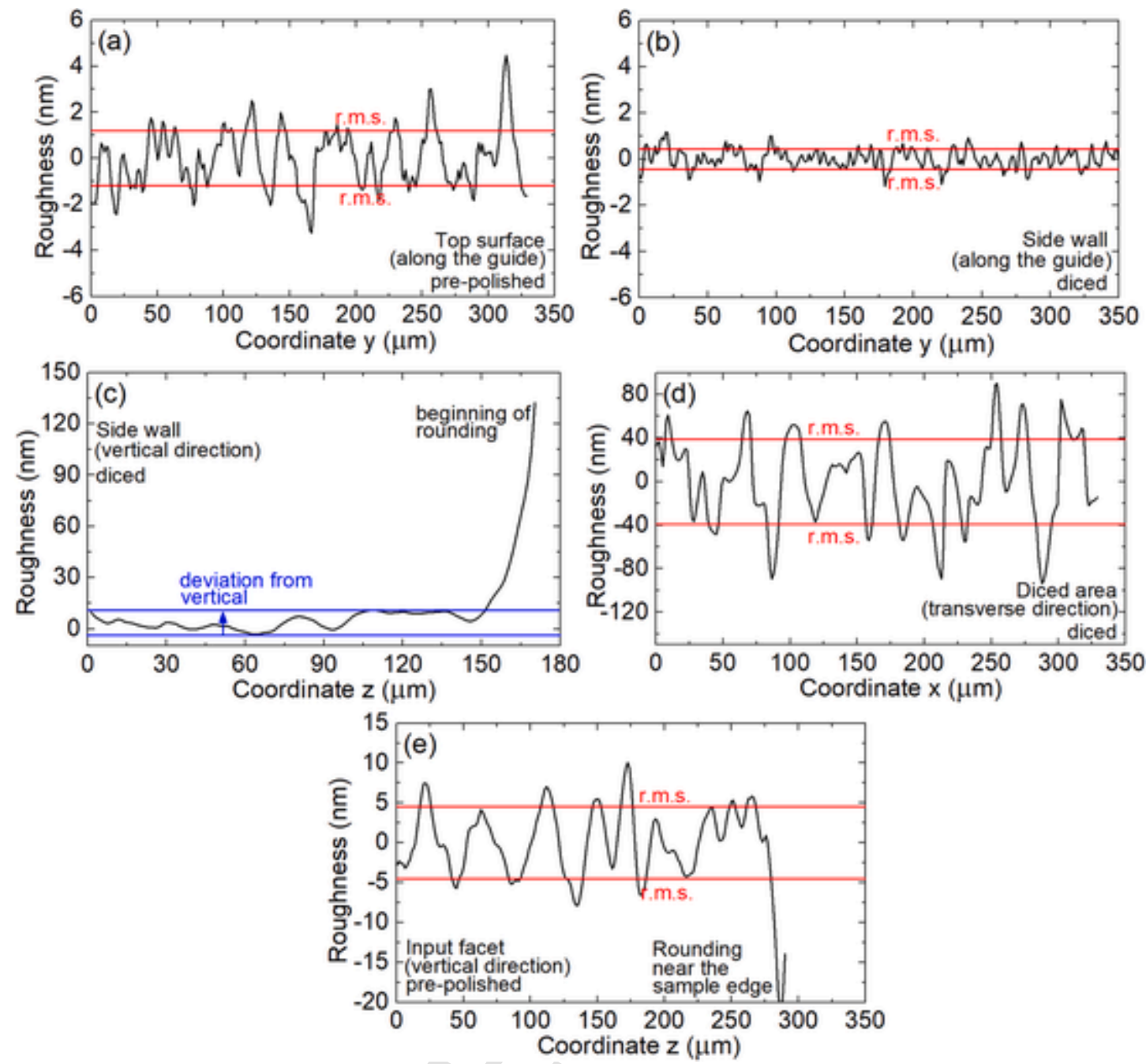

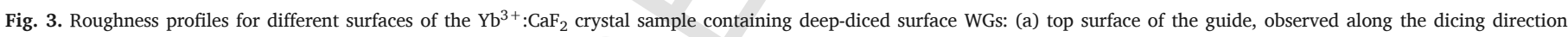

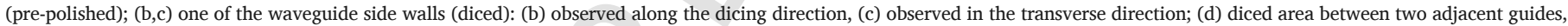
observed in the transverse direction (diced); (e) input facet of the guide, observed in the vertical direction (pre-polished). WG width: $40 \mu \mathrm{m}$, r.m.s. - root mean square value.

pump mirror (PM) coated for high transmission (HT, $T>97 \%$ ) at $0.88-0.99 \mu \mathrm{m}$ and for high reflection (HR, $\mathrm{R}>99.9 \%$ ) at $1.02-1.20 \mu \mathrm{m}$, and a set of flat output couplers (OCs) having a transmission in the range of $2 \%-50 \%( \pm 0.5 \%)$ at $1.0-1.1 \mu \mathrm{m}$. Both the PM and the OCs were placed close to the sample end-facets with minimum air gaps; no index-matching liquid was used to avoid the optical damage. The geometrical cavity length was $\sim 6.0 \mathrm{~mm}$.

As a pump source, we employed the CW Ti:Sapphire laser delivering up to $\sim 2.0 \mathrm{~W}$ at $979.5 \mathrm{~nm}$ corresponding to the fundamental mode $\left(\mathrm{M}^{2} \approx 1\right)$ and linear laser polarization. The incident pump power was varied by a rotatable half-wave plate and a Glan-Taylor polarizer setting the pump polarization to be vertical or horizontal. The pump was focused into the WGs using a spherical uncoated $\mathrm{CaF}_{2}$ lens ( $\mathrm{f}=40 \mathrm{~mm}$, $T=93.9 \%$ at $\sim 0.98 \mu \mathrm{m}$ ) through the PM. The measured pump spot size in the focus $2 w_{\mathrm{P}}$ was $27 \pm 5 \mu \mathrm{m}$. The pumping was in a single-pass. The pump beam was focused near the top of the ridge waveguides. The pump absorption at the threshold pump power was determined from pump-transmission measurements under non-lasing conditions. The laser output was collimated using another spherical $\mathrm{CaF}_{2}$ lens ( $\mathrm{f}=15 \mathrm{~mm}$ ). The residual pump was filtered out using a cut-off filter (FEL1000, Thorlabs). The profiles of the pump and laser modes in the near field were captured with the CCD camera. The scale calibration was performed as described above. The laser spectra were mea- sured using an optical spectrum analyzer (OSA, Ando AQ6315-E) with a spectral resolution of $0.1 \mathrm{~nm}$.

A photograph of the waveguide laser is shown in Fig. 6(b). The waveguides exhibited weak green upconversion luminescence owing to impurity $\mathrm{Er}^{3+}$ ions, Fig. 6(c).

\subsection{CW laser performance}

At first, we studied the laser performance of the intermediate $(40 \mu \mathrm{m}$ wide) waveguide for the optimum pump wavelength $\lambda_{\mathrm{p}}=979.5 \mathrm{~nm}$ (corresponding to zero-phonon-line (ZPL) of $\mathrm{Yb}^{3+}$ ions in $\mathrm{CaF}_{2}$ ). The laser generated a maximum output power of $723 \mathrm{~mW}$ at $1029-1051 \mathrm{~nm}$ (broad spectrum) with a slope efficiency $\eta$ of $76.0 \%$ ( $v s$. the absorbed pump power $P_{\text {abs }}$ ) and a laser threshold of $P_{\text {th }}=165 \mathrm{~mW}$ (for $T_{\mathrm{OC}}=20 \%$ ), Fig. 7 (a). The maximum optical-to-optical efficiency $v$. the pump power incident on the crystal $\eta_{\text {opt }}$ was $38.9 \%$. With increasing the output coupling, the laser threshold gradually increased, from $P_{\text {th }}=52 \mathrm{~mW} \quad\left(T_{\mathrm{OC}}=1 \%\right)$ to $394 \mathrm{~mW} \quad\left(T_{\mathrm{OC}}=50 \%\right)$. No thermal roll-over was observed up to the maximum available pump power. No fracture of the waveguide was observed as well. No lasing without the OC (i.e., relying on the Fresnel losses at the output facet) was observed probably due to the low refractive index of $\mathrm{CaF}_{2}(n=1.429$ at 

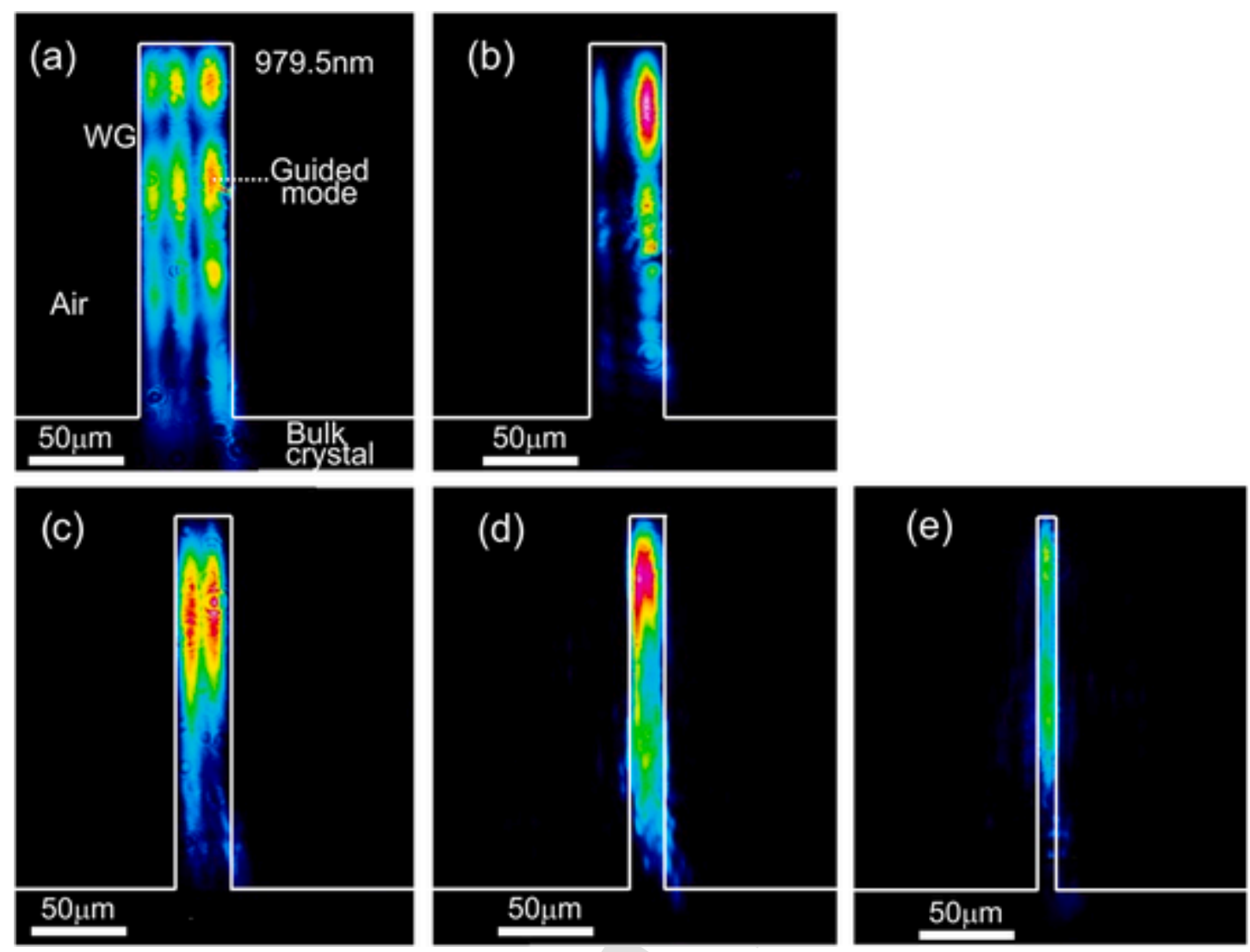

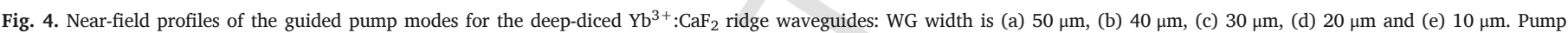
polarization: vertical, $\lambda_{\mathrm{p}}=979.5 \mathrm{~nm}$. White lines marking the air/crystal interfaces are drawn as guides for eyes.

$\sim 1.04 \mu \mathrm{m}$ [29]) leading to an equivalent $T_{\mathrm{OC}}$ as high as $96.9 \%$. The pump polarization in these studies was set to be vertical.

No lasing was achieved when pumping into the bulk area of the sample. This is due to the negative thermal lens in $\mathrm{Yb}^{3+}: \mathrm{CaF}_{2}[16]$ which drives a plano-plano cavity to an instability region. This observation confirms the waveguide geometry of the laser. On the other hand, negative thermal lens may promote the mode leakage into the substrate contributing to the total passive losses. However, this effect is expected to be diminished by reabsorption in unpumped regions of the waveguide.

The typical spectra of laser emission from the waveguide laser are shown in Fig. 7(b). The spectra are broad due to the smooth and broad gain spectra of $\mathrm{Yb}^{3+}$ ions in $\mathrm{CaF}_{2}$ and contains multiple lines originating from the Fabry-Perot (etalon) effects at the multiple crystal/air and mirror/air interfaces. With increasing the output coupling, the central emission wavelength experienced a blue-shift, from $\sim 1048 \mathrm{~nm}\left(T_{\mathrm{OC}}=1 \%\right)$ to $\sim 1029 \mathrm{~nm}\left(T_{\mathrm{OC}}=50 \%\right)$ due to the quasi-three-level nature of the ${ }^{2} \mathrm{~F}_{5 / 2} \rightarrow{ }^{2} \mathrm{~F}_{7 / 2}$ transition.

The Caird analysis [30] was applied, Fig. 7(c). The inverse of the slope efficiency, $1 / \eta$, was plotted $v s$. the inverse of the output-coupling loss, $1 / \gamma_{\mathrm{OC}}$, and the experimental data were fitted using the formula:

$1 / \eta=1 / \eta_{0}(1+2 \gamma / \gamma \mathrm{OC})$

where $\gamma_{\mathrm{OC}}$ and $\gamma$ (the loss coefficient) are given by:

$\gamma_{\mathrm{OC}}=-\ln \left(1-\mathrm{T}_{\mathrm{OC}}\right)$

$\gamma=-\ln (1-\mathrm{L})$

where $\eta_{0}$ is the intrinsic slope efficiency and $L$ is the single-pass passive loss. The use of Eq. (1) yields $\eta_{0}=75.0 \pm 4 \%$. The waveguide propagation losses are then calculated from $\mathrm{L}$ : dloss $=4.34 \mathrm{~L} / \mathrm{t}$,

leading to the value of $0.13 \pm 0.05 \mathrm{~dB} / \mathrm{cm}$ at $\sim 1.04 \mu \mathrm{m}$. This value agrees with that determined from the pump-transmission measurements $(0.21 \pm 0.06 \mathrm{~dB} / \mathrm{cm}$ at $\sim 0.91 \mu \mathrm{m})$ considering longer laser wavelength.

The determined $\delta_{\text {loss }}$ is smaller than the value corresponding to Fresnel losses at the crystal/air interfaces. Indeed, for a single pass and two reflections at the interfaces, $L_{\mathrm{Fr}}=6.1 \%$ and the equivalent $\delta_{\text {loss,Fr }}=0.44 \mathrm{~dB} / \mathrm{cm}$. This is due to the fact that the input and output faces of the crystal were polished with a good parallelism (value) so that the crystal itself acted as an etalon, so that the generated longitudinal modes experienced much lower losses.

The measured single-pass pump absorption, $\eta_{\mathrm{abs}, \mathrm{NL}}$ as a function of the incident pump power is plotted in Fig. 7(d). It gradually increased from the small-signal value, $\eta_{\mathrm{abs} 0}$ :

$\eta_{\mathrm{abs} 0}=1-\exp \left(-\sigma \mathrm{p}_{\mathrm{abs}} \mathrm{N}_{\mathrm{Yb}} \mathrm{t}\right)$

where $\sigma^{\mathrm{p}}$ abs is the absorption cross-section at the pump wavelength $\left(0.54 \times 10^{-20} \mathrm{~cm}^{2}\right.$ at $\left.979.5 \mathrm{~nm}\right)$ indicating the effect of ground-state bleaching. In our case, according to Eq. (4), $\eta_{\mathrm{abs} 0}=97.2 \%$. With increasing the output coupling, due to increased inversion in the waveguide, the pump absorption at the threshold pump power $\eta_{\text {abs,th }}$ dropped from $92.7 \%\left(\mathrm{~T}_{\mathrm{OC}}=1 \%\right)$ to $68.2 \%\left(\mathrm{~T}_{\mathrm{OC}}=50 \%\right)$.

The laser excitation curve (the plot of the output power $v s$. the pump wavelength) was measured for the $40 \mu \mathrm{m}$ wide waveguide ensuring a constant value of the incident pump power, as shown in Fig. 8(a). Laser operation was achieved for $\lambda_{\mathrm{p}}$ in the range of 908.9-996.3 nm. The laser excitation curve well matched with the absorption cross-section spectrum for the ${ }^{2} \mathrm{~F}_{7 / 2} \rightarrow{ }^{2} \mathrm{~F}_{5 / 2} \mathrm{Yb}^{3+}$ transition in $\mathrm{CaF}_{2}$. The emission linewidth for the Ti:Sapphire laser was $<0.1 \mathrm{~nm}$. 



Fig. 5. Evaluation of the waveguide propagation losses $\delta_{\text {loss }}$ (at $\lambda=912 \mathrm{~nm}$ ) in deep-diced ridge WGs in $\mathrm{Yb}^{3+}: \mathrm{CaF}_{2}$ : the pump polarization is (a) vertical and (b) horizontal. Symbols - experimental data on light intensities along the guides, lines - their exponential fits considering the total loss $\left(\delta_{\text {loss }}+\delta_{\text {abs }}\right)$.

Table 1

Measured pump coupling efficiency $\eta_{\text {coupl }}$ (at $\lambda=892 \mathrm{~nm}$ ) and waveguide propagation losses $\delta_{\text {loss }}\left(\right.$ at $\lambda=912 \mathrm{~nm}$ ) for deep-diced ridge waveguides in $\mathrm{Yb}^{3+}: \mathrm{CaF}_{2}$.

\begin{tabular}{llll}
\hline WG width & $\eta_{\text {coupl }} \%$ & $\delta_{\text {loss }}, \mathrm{dB} / \mathrm{cm}$ & \\
\hline & & $E \|$ vertical & $E \|$ horizontal \\
\hline $50 \mu \mathrm{m}$ & $77.9 \pm 0.5$ & $0.17 \pm 0.05$ & $0.34 \pm 0.07$ \\
$40 \mu \mathrm{m}$ & $74.2 \pm 0.5$ & $0.21 \pm 0.06$ & $0.39 \pm 0.07$ \\
$30 \mu \mathrm{m}$ & $67.9 \pm 0.5$ & $0.28 \pm 0.07$ & $0.44 \pm 0.1$ \\
$20 \mu \mathrm{m}$ & $57.6 \pm 0.7$ & $0.35 \pm 0.1$ & $0.46 \pm 0.1$ \\
$10 \mu \mathrm{m}$ & $43.0 \pm 1.0$ & $0.52 \pm 0.1$ & $0.91 \pm 0.2$ \\
\hline
\end{tabular}

We also tried pumping of the waveguide into another absorption peak of $\mathrm{Yb}^{3+}$ ions at 922.0 which is much broader, Fig. 8(b). In this case, the laser generated a maximum output power of only $521 \mathrm{~mW}$ at $1019-1038 \mathrm{~nm}$ with a maximum $\eta_{\mathrm{opt}}=22.5 \%$. Moreover, a thermal roll-over was observed for $P_{\text {inc }}>1.7 \mathrm{~W}$. Such deterioration of the laser performance with respect to pumping at $979.5 \mathrm{~nm}$ is mainly due to higher fractional heat loading:

$\eta_{\mathrm{h}} \approx 1-\eta_{\mathrm{St}, \mathrm{L}, \text { where }} \eta_{\mathrm{St}, \mathrm{L}}=\gamma_{\mathrm{p}} / \gamma_{\mathrm{L}}$

where $\eta_{\mathrm{St}, \mathrm{L}}$ is the Stokes efficiency under laser conditions and $\lambda_{\mathrm{L}}$ is the laser wavelength. Indeed, $\eta_{\mathrm{h}}=10.7 \%$ and $5.2 \%$ for pumping at the short-wavelength part of the absorption spectrum and at the ZPL, respectively.
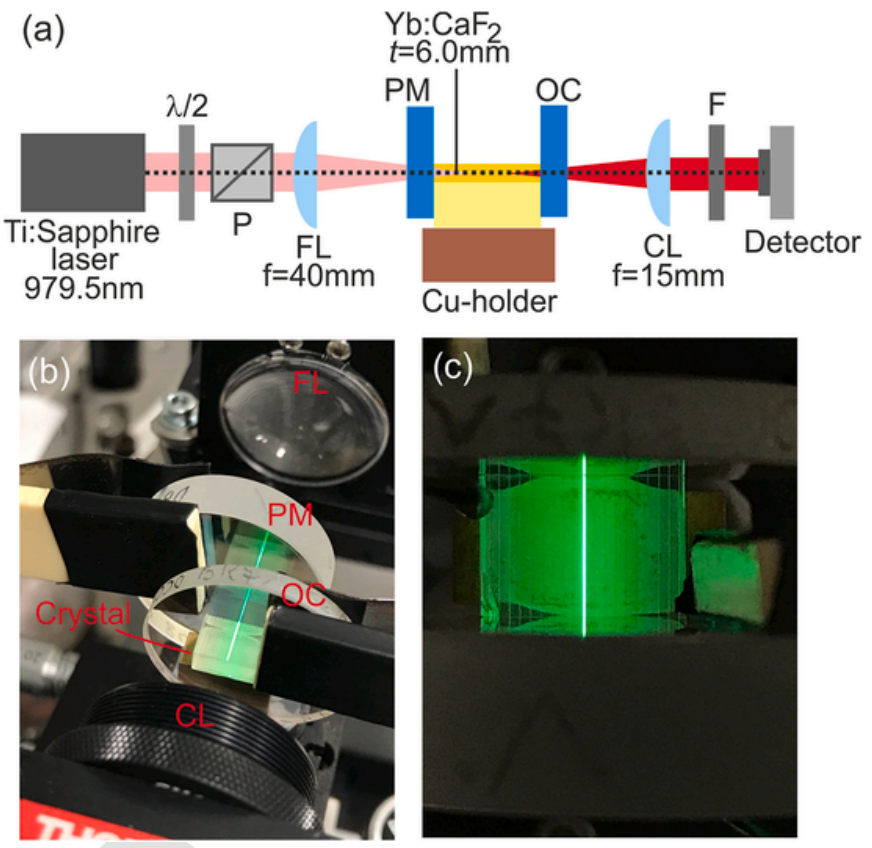

Fig. 6. Deep-diced $\mathrm{Yb}^{3+}: \mathrm{CaF}_{2}$ ridge waveguide laser: (a) scheme of the laser, $\lambda / 2-$ half-wave plate, P - Glan-Taylor polarizer, PM - pump mirror, OC - output coupler, FL and CL - focusing and collimating lenses, respectively, F -cut-off filter; (b) photograph of the laser; (c) top view photograph of the pumped guide.

We have directly compared the laser performance of all WGs (widths: 10-50 $\mu \mathrm{m}$ ), see Fig. 9(a). In general, for narrower WGs, the pump coupling efficiency decreased while the ground-state bleaching increased due to the higher pump intensity. Both effects limited the power scaling capabilities. Indeed, for the same output coupling $\left(T_{\mathrm{OC}}=20 \%\right)$, $\eta_{\mathrm{abs}, \text { th }}$ dropped from $84.3 \%$ (50 $\mu \mathrm{m}$ waveguide) to $76.7 \%$ (10 $\mu \mathrm{m}$ one). The performance of the $40 \mu \mathrm{m}$ and $50 \mu \mathrm{m}$ waveguides was similar. For the intermediate size waveguide $(30 \mu \mathrm{m})$, the laser operated with even higher slope efficiency $\eta=79.5 \%$ and reduced laser threshold $\left(P_{\text {th }}=98 \mathrm{~mW}\right)$ while the power scaling was limited to $635 \mathrm{~mW}$ at $1039-1051 \mathrm{~nm}$ as explained above. For even smaller structures $(10-20 \mu \mathrm{m})$, the laser performance gradually deteriorated and the threshold was nearly unchanged. Moreover, for the $10 \mu \mathrm{m}$ waveguide, a thermal roll-over was observed. There are two main reasons for this behavior: (i) higher propagation losses for smaller ridges, cf. Table 1, and (ii) worse thermal management of thin waveguides which provide almost no heat flow in the vertical direction.

The spectra of laser emission for WGs with different width are compared in Fig. 9(b). They are similar except of the smallest structures $(10-20 \mu \mathrm{m})$ for which the central wavelength experienced a slight blue-shift to $\sim 1034 \mathrm{~nm}$ due to increased passive losses.

The near-field mode profiles for all the studied WGs are shown in Fig. 10(a). The laser modes are localized near the top part of the waveguide. With decreasing the waveguide width, the mode ellipticity:

$\mathrm{e}=\left(\mathrm{w}_{\mathrm{Ly}}-\mathrm{w}_{\mathrm{Lx}}\right) / \mathrm{w}_{\mathrm{Ly}}$

along the vertical direction gradually increases, i.e., from $e=0.41$ for $50 \mu \mathrm{m}$ wide waveguide to $e=0.88$ for $10 \mu \mathrm{m}$ wide one. For larger waveguides $(40-50 \mu \mathrm{m})$, the mode was well localized within the ridge (e.g., the mode size $2 w_{\mathrm{Lx}}=38 \mu \mathrm{m}$ for the $50 \mu \mathrm{m}$ wide waveguide) and for smaller ones $(10-20 \mu \mathrm{m})$, the mode overlap with the side walls of the ridge increased (as indicated by the mode size $2 w_{\mathrm{Lx}}=12 \mu \mathrm{m}$ for the $10 \mu \mathrm{m}$ wide waveguide). These changes in the mode profile may explain higher propagation losses in the latter case.

The typical 1D intensity profiles of the laser mode from the $40 \mu \mathrm{m}$ wide waveguide measured in the near-field are shown in Fig. 11(a). In 

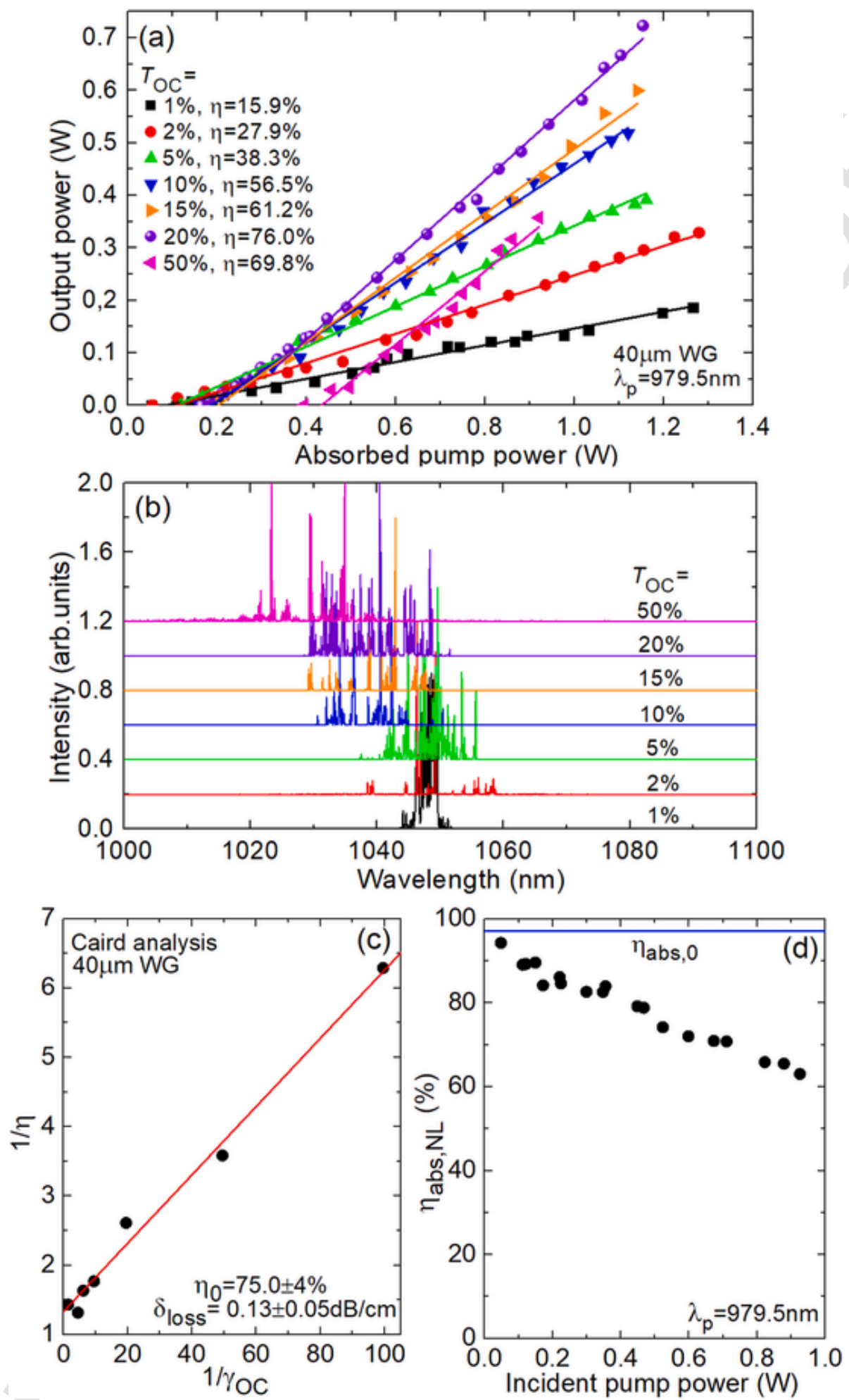

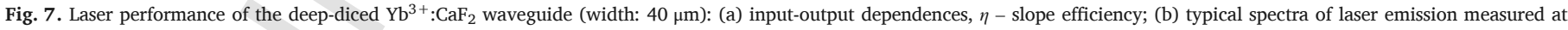

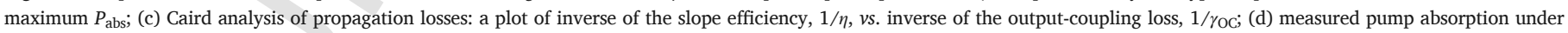
non-lasing conditions (single-pass), $\eta_{\mathrm{abs}, \mathrm{NL}}$. The small-signal absorption, $\eta_{\mathrm{abs}, 0}$, is given for comparison. Pump polarization: vertical, $\lambda_{\mathrm{p}}=979.5 \mathrm{~nm}$.

the horizontal direction, the profile is well fitted with a Gaussian function (goodness of the fit: $\mathrm{R}^{2}>0.99$ ) and the mode size $2 w_{\mathrm{Lx}}=26 \mu \mathrm{m}$. In the vertical direction, the beam is slightly multimode with $2 w_{\mathrm{Ly}}=62 \mu \mathrm{m}(e=0.58)$. The beam quality factors were measured in the far field by the ISO-standard method [31] using an uncoated spherical $\mathrm{CaF}_{2}$ lens ( $\mathrm{f}=75 \mathrm{~mm}$ ) placed after the output coupler, see Fig. 11(b). The obtained values are $\mathrm{M}^{2}{ }_{\mathrm{x}}=1.05 \pm 0.05$ and $\mathrm{M}_{\mathrm{y}}^{2}=1.3 \pm 0.1$ in agreement with the previous considerations.

Calcium fluoride is cubic and optically isotropic. However, the studied $\mathrm{Yb}^{3+}: \mathrm{CaF}_{2}$ waveguide lasers generated partially polarized emission. Depending on the waveguide width, the polarization degree $P$ and the angle of the preferential orientation of the electric field $\phi$ (with respect 

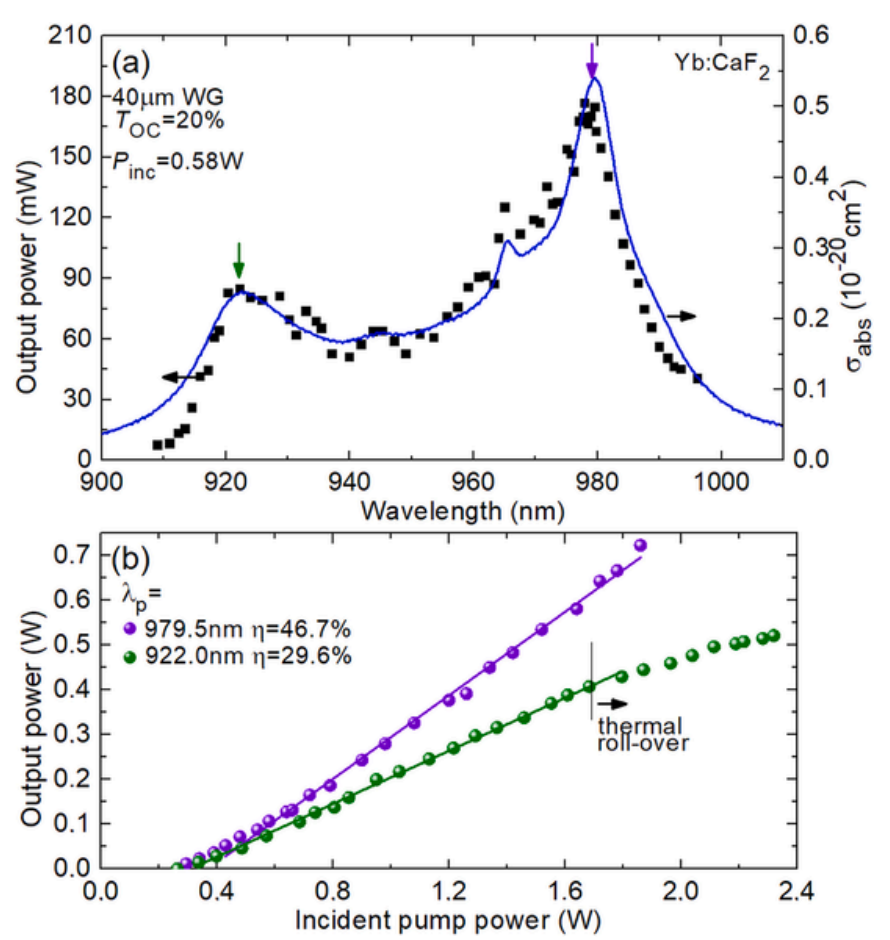

Fig. 8. Effect of the pump wavelength on the performance of the deep-diced $\mathrm{Yb}^{3+}: \mathrm{CaF}_{2}$ waveguide laser (width: $40 \mu \mathrm{m}$ ): (a) laser excitation curve (output power $v s$. the pump wavelength), $P_{\text {inc }}=0.58 \mathrm{~W}$, the absorption cross-section, $\sigma_{\mathrm{abs}}$, is shown for comparison, vertical arrows indicate two selected pump wavelengths; (b) input-output dependences for $\lambda_{\mathrm{p}}=979.5 \mathrm{~nm}$ and $922.0 \mathrm{~nm}$. Pump polarization: vertical, $T_{\mathrm{OC}}=20 \%$.
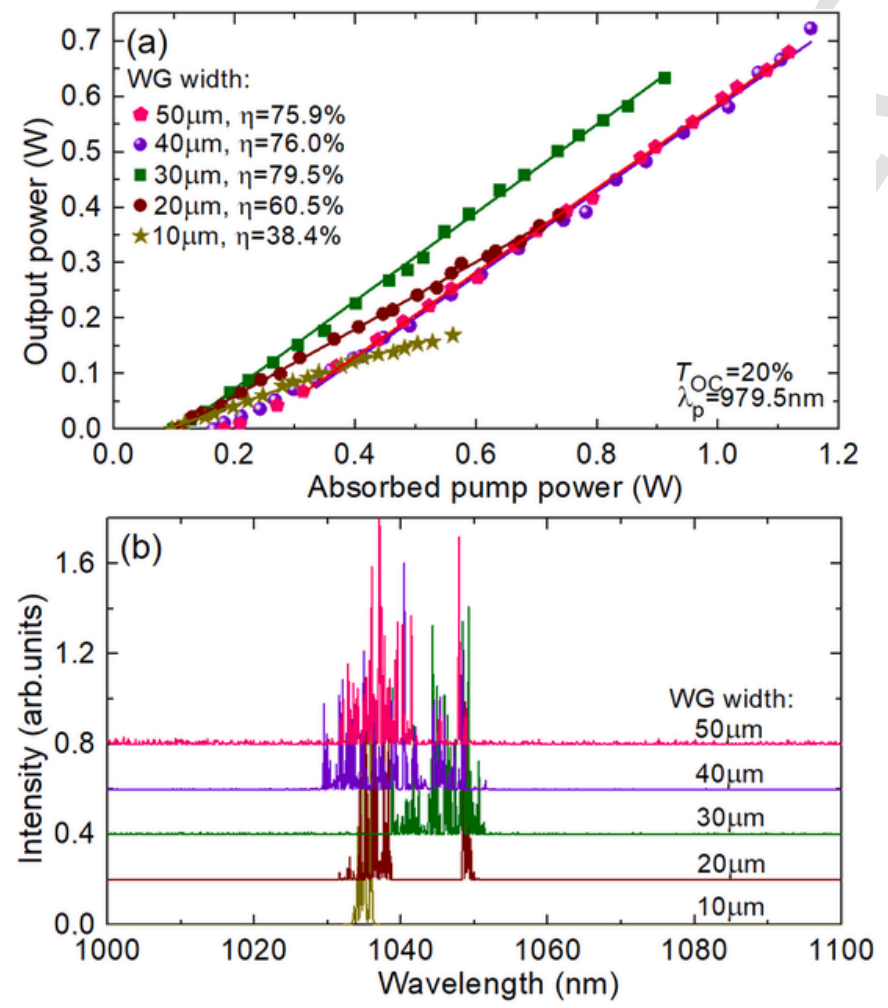

Fig. 9. Effect of the waveguide width on the performance of the deep-diced $\mathrm{Yb}^{3+}: \mathrm{CaF}_{2}$ waveguide lasers: (a) input-output dependences, $\eta$ - slope efficiency; (b) typical spectra of laser emission measured at maximum $P_{\text {abs. }}$ Pump polarization: vertical, $\lambda_{\mathrm{p}}=979.5 \mathrm{~nm}$, $T_{\mathrm{OC}}=20 \%$. to the pump polarization $\boldsymbol{E}_{\mathrm{p}}$ which was fixed to be vertical) varied. This is revealed in Fig. 12 where the power transmitted through a rotating Glan-Taylor polarizer is plotted as a function of its rotation angle $\theta$. The angle $\theta=0$ corresponds to horizontal orientation of the polarizer. The curves are well fitted using the formula:

$\mathrm{P}_{\text {out }}(\theta)=\mathrm{P}_{\mathrm{u}} / 2+\mathrm{P}_{\mathrm{p}} \cos ^{2}[\theta$

- $\left.\left(90^{\circ}-\phi\right)\right]$

suggesting partially polarized light. The polarization degree is then:

$\mathrm{P}=\mathrm{Pp} /\left(\mathrm{P}_{\mathrm{p}}+\mathrm{P}_{\mathrm{u}}\right)$

For example, for the $20 \mu \mathrm{m}$ wide waveguide, $P=96 \%$ and $\phi=5^{\circ}$ (high polarization degree, almost vertical linear polarization well matching the pump polarization state) and for the $50 \mu \mathrm{m}$ one, $P=92 \%$ and $\phi=53^{\circ}$ (lower polarization degree, stronger rotation of the preferential orientation of the electric field for laser emission with respect to the pump polarization). One possible explanation for this tendency can be the observed anisotropy of waveguide propagation losses for TM and TE polarizations, Table 1 . As this anisotropy becomes more significant for narrower waveguides, predominantly vertically polarized laser emission is generated.

To further reveal the anisotropic polarization response of the fabricated ridges, we studied the laser performance of the same waveguide (40 $\mu \mathrm{m}$ wide) under two different pump polarizations (vertical and horizontal). In the latter case, the $\mathrm{Yb}^{3+}: \mathrm{CaF}_{2}$ waveguide laser generated an output power of $457 \mathrm{~mW}$ at $1033-1044 \mathrm{~nm}$ with $\eta$ of only $52.9 \%$ and $P_{\text {th }}$ of $238 \mathrm{~mW}$, as shown in Fig. 13(a and b). The observed lower slope efficiency and increased laser threshold (as compared to the case of vertical pump polarization) are in line with the higher propagation losses for TE pumping, see Table 1. The corresponding pump and laser modes are shown in Fig. 13(c-f). For the horizontal pump polarization, the leakage of the pump mode into the bulk area of the sample is more pronounced. The laser mode also exhibits stronger ellipticity in the vertical direction.

\subsection{Tunable operation}

To demonstrate wavelength tuning in the developed waveguide laser, the flat $\mathrm{OC}$ was replaced by a concave one (radius of curvature, RoC, of $-100 \mathrm{~mm}$ ) with a similar coating $\left(T_{\mathrm{OC}}=2 \pm 0.5 \%\right.$ at $1.0-1.1 \mu \mathrm{m}$ ) placed at $\sim 94 \mathrm{~mm}$ apart from the output facet of the sample (a nearly hemispherical cavity design). As a tuning element, we used an uncoated quartz birefringent plate BIR1020, Newlight Photonics) with a diameter of $1^{\prime \prime}$ and a thickness of $2.0 \mathrm{~mm}$. It was $\boldsymbol{a}$-cut with the optical axis ( $\boldsymbol{c}$-axis) lying in the plane of the plate. The plate was placed at the Brewster angle near the output facet of the sample. The pump polarization was vertical and the pump wavelength $\lambda_{\mathrm{p}}$ was $979.5 \mathrm{~nm}$.

Prior to the tuning experiment, we studied the laser operation in the free-running regime (when removing the filter from the cavity). The laser generated a maximum output power of $194 \mathrm{~mW}$ at $1036-1057 \mathrm{~nm}$ with a slope efficiency of $23.1 \%$ and a laser threshold of $150 \mathrm{~mW}$. The laser performance slightly deteriorated as compared to the plano-plano cavity with the same OC, cf. Fig. 7(a), namely $329 \mathrm{~mW}$ at 1038-1059 nm with $\eta=27.9 \%$ and $P_{\text {th }}=55 \mathrm{~mW}$, due to higher intracavity losses related to the back-coupling efficiency at the output facet of the ridge.

After inserting the birefringent plate, a continuous wavelength tuning between 1009.2 and $1072.4 \mathrm{~nm}$ was demonstrated, as shown in Fig. 14 (a). This corresponded to a tuning range of $\sim 63 \mathrm{~nm}$. The maximum of the tuning curve was observed at $1052 \mathrm{~nm}$ for an output power of $118 \mathrm{~mW}$. This value is lower than that for the free-running operation because of the insertion loss of the BRF. One may also argue that the 

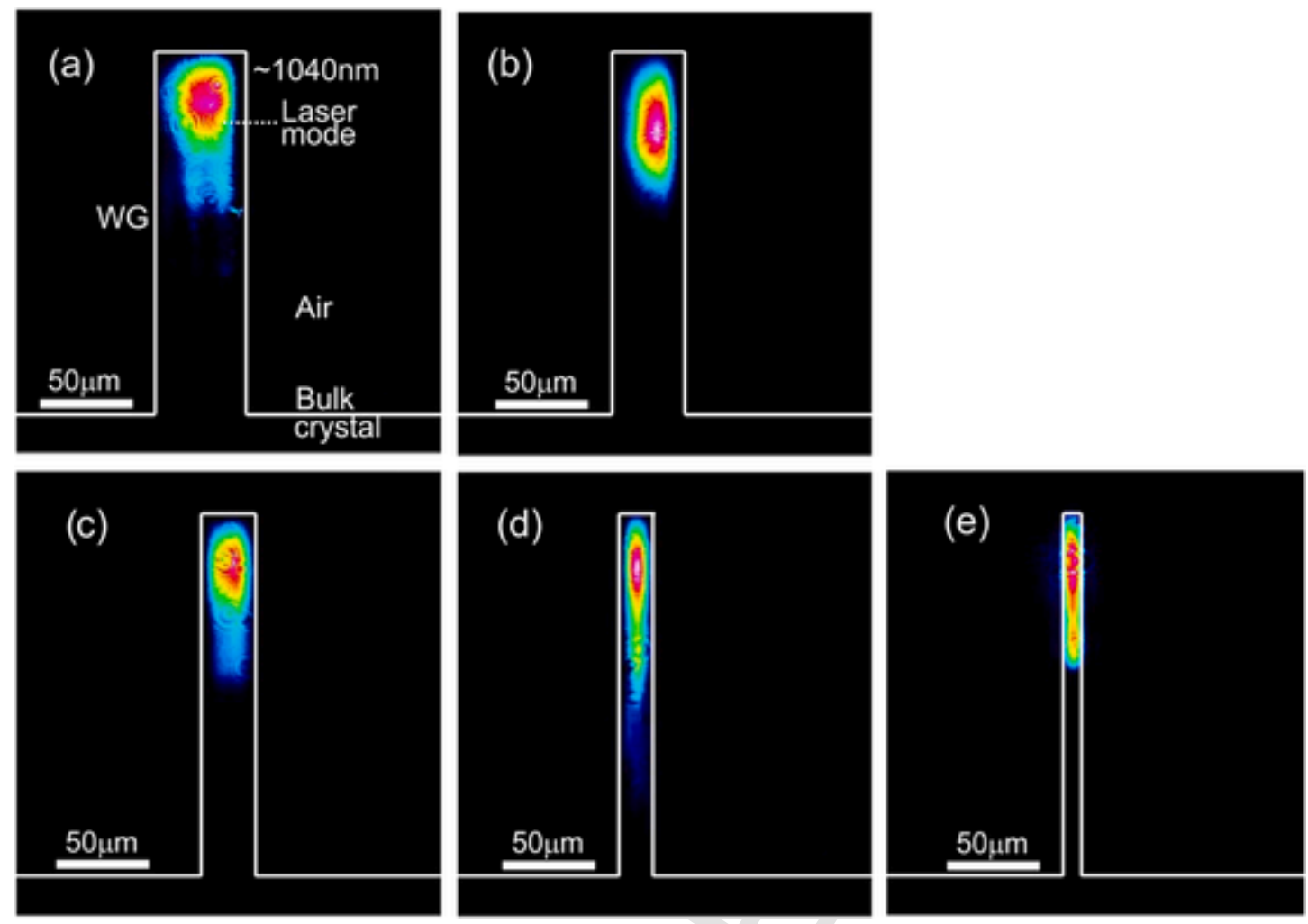

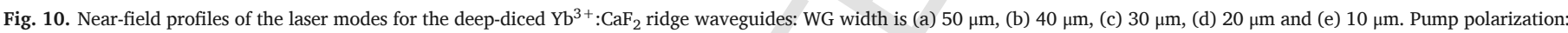
vertical, $\lambda_{\mathrm{p}}=979.5 \mathrm{~nm}, P_{\mathrm{abs}} \sim 0.5 \mathrm{~W}, T_{\mathrm{OC}}=20 \%$. White lines marking the air/crystal interfaces are drawn as guides for eyes.
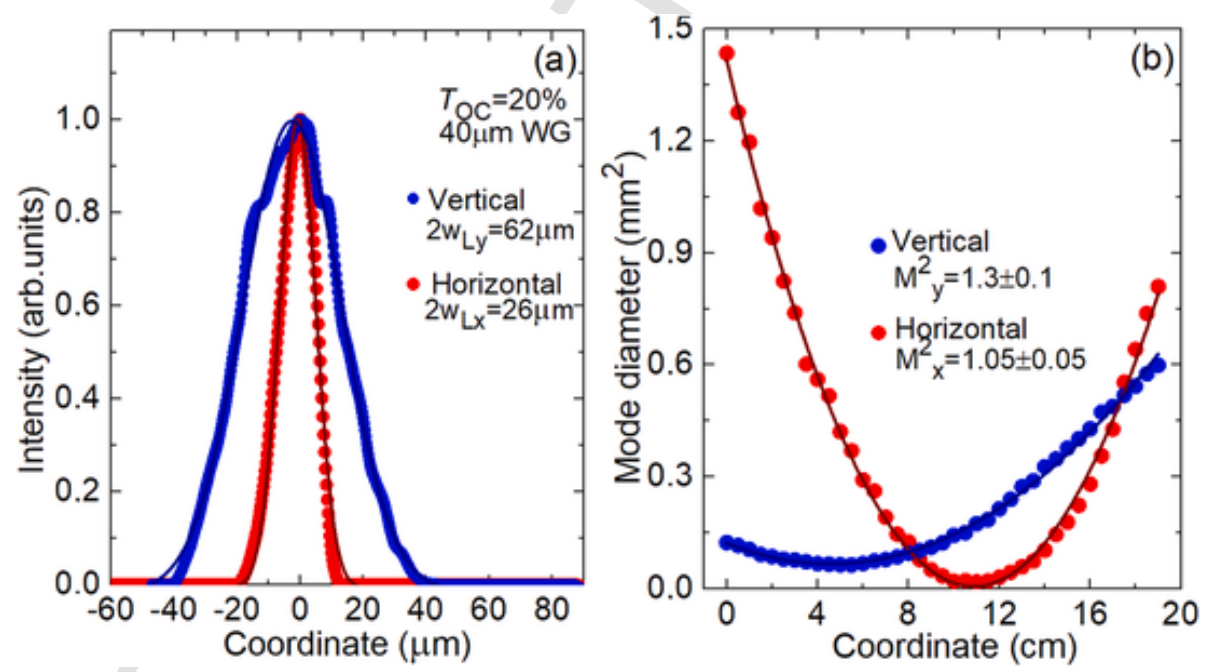

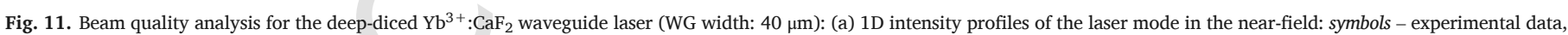
curves - Gaussian fits; (b) evaluation of the beam quality factors $\mathrm{M}_{\mathrm{x}, \mathrm{y}}^{2}$ in the far-field, $T_{\mathrm{OC}}=20 \%, P_{\mathrm{abs}} \sim 0.5 \mathrm{~W}$. Pump polarization: vertical.

horizontal polarization of laser emission determined by the Brewster-oriented BRF leads to slightly higher propagation losses. In the same figure, we show the gain spectra for $\mathrm{Yb}^{3+}$ ions in $\mathrm{CaF}_{2} . \mathrm{Yb}^{3+}$ ions represent a quasi-three-level laser scheme with reabsorption, so that the gain cross-se

$\sigma_{\mathrm{g}}=\beta \sigma_{\mathrm{SE}}-(1-\beta) \sigma_{\mathrm{abs}}$

are calculated to conclude about the laser wavelength. Here, $\beta=N_{2}\left({ }^{2} \mathrm{~F}_{5 / 2}\right) / N_{\mathrm{Yb}}$ is the inversion ratio and $N_{2}$ is the population of the upper laser level. Owing to the strong ion clustering in $\mathrm{Yb}^{3+}: \mathrm{CaF}_{2}$, it exhibits smooth and broad gain spectra showing several local maxima at $\sim 1052,1032$ and $1018 \mathrm{~nm}$. The former local maximum well matches with the maximum of the tuning curve. The shape of the latter is determined by both the gain spectrum and the coatings of the PM and OC (in particular, an abrupt rise of transmission of PM below $1020 \mathrm{~nm}$ ).

The typical spectra of emission from the wavelength-tunable waveguide laser are shown in Fig. 14(b). They are relatively narrow (linewidth: $<0.5 \mathrm{~nm}$ ), compare with the broad spectrum containing multiple lines for the laser operating in the free-running regime. 


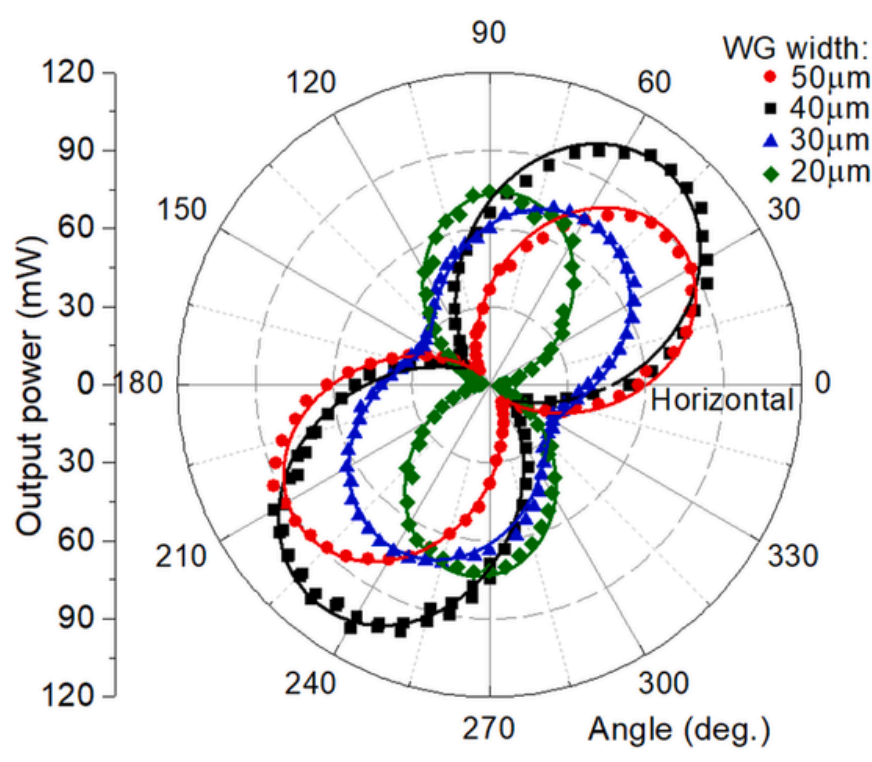

Fig. 12. Analysis of the polarization state of emission of the deep-diced $\mathrm{Yb}^{3+}: \mathrm{CaF}_{2}$ waveguide lasers (WG width: $20-50 \mu \mathrm{m}$ ): transmitted output power after the Glan-Taylor polarizer vs. its angular position. $T_{\mathrm{OC}}=20 \%, P_{\mathrm{inc}} \sim 0.75 \mathrm{~W}$. Pump polarization: vertical $\left(90^{\circ}\right)$.

\subsection{Discussion}

The results on $\mathrm{Yb}^{3+}$-doped calcium fluoride waveguide lasers achieved so far are summarized in Table 2 focusing in particular on the output power, slope efficiency and optical-to-optical efficiency. Two methods were applied previously to fabrication of laser-active WGs, namely, ULI also using bulk doped crystals (as in the present work) and LPE growth of thin single-crystalline layers on bulk undoped substrates. In the present work, we report on the highest output power and slope efficiency (achieved with high output coupling, $T_{\mathrm{OC}}=20 \%$ ) and the smallest laser threshold (for small $T_{\mathrm{OC}}=2 \%$ ) as compared to the previous works. We also report on the relatively low propagation losses compared to those for the LPE method. In terms of the overall optical-to-optical efficiency vs. the input pump power, our work still leaves a space for further improvement. We believe that $\eta_{\text {opt }}$ may excee $50 \%$ via optimization of the pump coupling (which can be potentially limited only by the Fresnel losses considering large cross-sectional area of the waveguides and high refractive index contrast at the crystal/air interfaces) and using longer waveguides $\left(>1 \mathrm{~cm}\right.$ ) and/or higher $\mathrm{Yb}^{3+}$ doping levels ensuring nearly complete pump absorption.

The tuning range achieved for the $\mathrm{Yb}^{3+}: \mathrm{CaF}_{2}$ waveguide laser $(\sim 63 \mathrm{~nm})$ is comparable with the best results obtained with the corresponding bulk crystals. Petit et al. reported on a Ti:Sapphire pumped bulk 1.7 at. $\% \mathrm{Yb}^{3+}: \mathrm{CaF}_{2}$ laser with a Lyot filter which was continuously tunable between $\sim 1000$ and $1060 \mathrm{~nm}$ [20]. Lucca et al. demonstrated tuning of a diode-pumped 5 at.\% $\mathrm{Yb}^{3+}: \mathrm{CaF}_{2}$ laser between 1017.8 and $1072.1 \mathrm{~nm}$ (tuning range: $54 \mathrm{~nm}$ ) with a power maximum at $\sim 1052 \mathrm{~nm}$ [19] which agrees with the present work.

Recently, we applied the same concept of deep diamond saw dicing for $\mathrm{Tm}^{3+}: \mathrm{LiYF}_{4}$ crystal [15]. The following mechanisms of mode guiding in the fabricated ridges were suggested: (i) high refractive index contrast at three crystal-air interfaces, (ii) reabsorption losses in the unpumped (non-bleached) regions of the waveguide, and (iii) possible variation of the refractive index due to the stresses induced by dicing via the photo-elastic effect. Note that tetragonal $\mathrm{LiYF}_{4}$ is optically anisotropic and exhibits natural birefringence. Indeed, the polarization state in the $\mathrm{Tm}^{3+}: \mathrm{LiYF}_{4}$ waveguide laser was determined by the gain anisotropy (vertical, $\pi$ ). The inherent optical anisotropy of $\mathrm{LiYF}_{4}$ may promote the waveguiding properties of diamond saw diced ridges. Here, we prove that deep diamond saw dicing can be also applied to fabrication of ridge WGs in optically isotropic (fluoride) materials. We also observe additional indications of anisotropic stress fields in the microstructure sample (i.e., the polarization-sensitive response of the waveguides) which can be promoted by slightly asymmetric shape of the bottom part of the ridges.

One may argue that the observed lasing is related to the bulk crystal geometry (i.e., not the waveguide one). When focusing the pump into the bulk (non-diced) area of the sample, no laser action was observed. This is because $\mathrm{Yb}^{3+}: \mathrm{CaF}_{2}$ exhibits a negative (defocusing) thermal lens due to the negative $\mathrm{d} n / \mathrm{d} T$ coefficient, $-11.3 \times 10^{-6} \mathrm{~K}^{-1}$ [16]. Negative thermal lens makes the plano-plano cavity unstable. As for the waveguide laser experiments, negative thermal lens seems to be weaker than the index-guiding mechanism. However, it may contribute to the mode leakage into the bulk area of the sample.

As a final comment, in the previous work with $\mathrm{Tm}^{3+}: \mathrm{LiYF}_{4}$ [15], we detected significant thermal effects preventing power scaling. In the present work, the waveguide laser operated in true CW regime and no thermal roll-over was observed up to at least $P_{\text {inc }} \sim 1.2 \mathrm{~W}$ (when pumping into the zero-phonon-line absorption peak of $\mathrm{Yb}^{3+}$ ions and avoiding the use of very narrow waveguides with the widths below $20 \mu \mathrm{m}$ ). There are two main reasons for that. First, $\mathrm{Tm}^{3+}$ laser scheme provides higher heat loading $\left(\eta_{\mathrm{h}} \sim 28 \%\right.$ for $\left.\mathrm{Tm}^{3+}: \mathrm{LiYF}_{4}[32]\right)$ as compared to the in-band pumped $\mathrm{Yb}^{3+}$ lasers $\left(\eta_{\mathrm{h}}=5.2 \%\right.$, see above). Second, the thermal conductivity of $\mathrm{CaF}_{2}$ is higher [17].

In the present study, the power scaling of the $\mathrm{Yb}^{3+}: \mathrm{CaF}_{2}$ waveguide laser was limited by the available pump (the Ti:Sapphire laser). We believe that further power scaling reaching multi-watt output in true continuous-wave regime is feasible when using other high-brightness pump sources, e.g., fiber lasers, or even fiber-coupled InGaAs laser diodes. In the latter case, broader ridges $(50 \mu \mathrm{m})$ would be preferable. The main limitation for power scaling in CW regime would be the thermal roll-over due to the limited heat removal from the ridge (which is possible only along the vertical direction, towards the bulk/undiced area) but not the damage of the waveguide input faces. The excessive heating of the ridge may induce additional losses owing to the mode leakage induced by the negative thermal lens. We suppose that it can be overcame to a certain extent by active cooling of the sample.

\section{Conclusions}

To conclude, deep diamond saw dicing (featuring high height-to-width aspect ratios of the microstructures) is a powerful approach to fabricate surface (ridge) waveguides in bulk ytterbium-doped calcium fluoride crystals for laser applications. Such waveguides ensure relatively low propagation losses (down to $0.13 \pm 0.05 \mathrm{~dB} / \mathrm{cm}$ at $\sim 1 \mu \mathrm{m}$ ), small surface roughness of the side walls (about $0.5 \mathrm{~nm}$ ), good verticality of the ridges (within $15 \mathrm{~nm}$ for the upper $3 / 4$ part of the ridge) and the lack of cracking/chipping, as well as dicing debries. No post-processing polishing is required for such microstructures.

The combination of good thermal properties of $\mathrm{CaF}_{2}$ with the broadband emission of $\mathrm{Yb}^{3+}$ ions which are subjected to strong ion clustering determine the power scaling capabilities of deep diced $\mathrm{Yb}^{3+}: \mathrm{CaF}_{2}$ waveguide lasers, as well as the possibility of broadband wavelength tuning. In the present work, using deep-diced $\mathrm{Yb}^{3+}: \mathrm{CaF}_{2}$ ridge WGs, we achieved the output powers up to $723 \mathrm{~mW}$ at $\sim 1.04 \mu \mathrm{m}$ with a slope efficiency of $76.0 \%$ (for high output-coupling) and the laser thresholds as low as $55 \mathrm{~mW}$ (for small output coupling). These parameters represent the record-high values for ytterbium calcium fluoride waveguide lasers. Moreover, we demonstrated continuous wavelength tuning of the waveguide laser between 1009.2 and $1072.4 \mathrm{~nm}$ which is comparable with the best results for the corresponding bulk crystals.

The nature of waveguiding in deep-diced ridges has to be further clarified. In the present work with the cubic (optically isotropic) $\mathrm{CaF}_{2}$ 

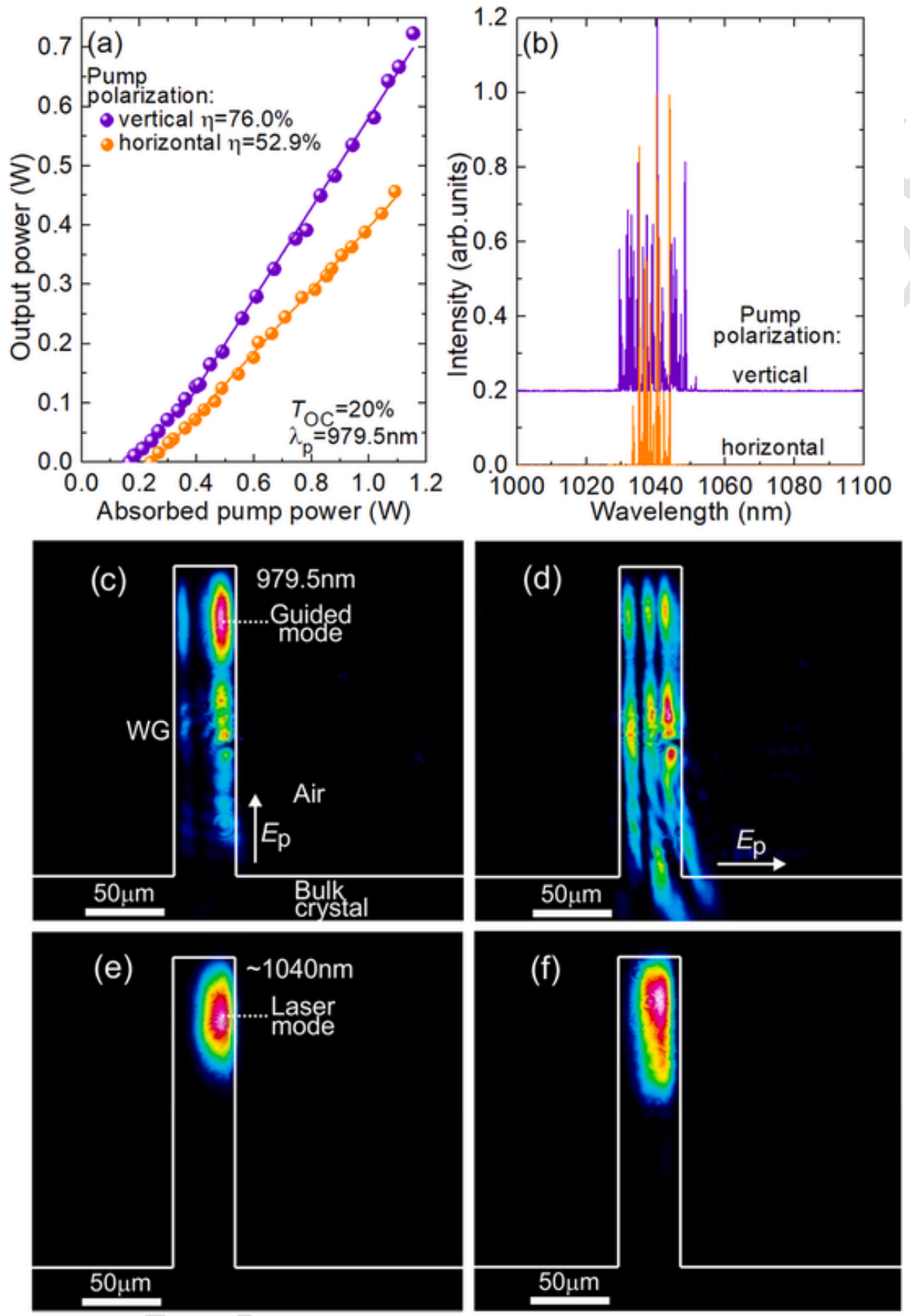

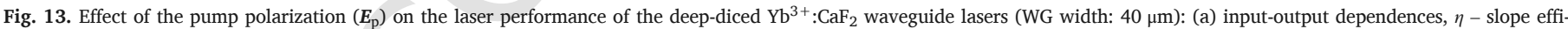

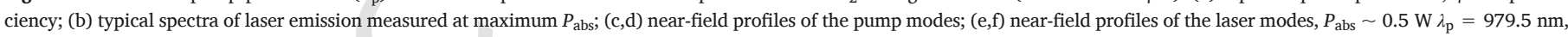
$T_{\mathrm{OC}}=20 \%$. In (c-f), white lines marking the air/crystal interfaces are drawn as guides for eyes.

crystal, we observed a notable polarization-response of the fabricated waveguides, namely, a great difference of the propagation losses for TM and TE polarized light, as well as linearly polarized laser emission. These observations may suggest an anisotropic stress field in the ridges modifying the refractive index.

Further work should focus on the optimization of the transverse profile of the ridges for simultaneously maintaining good mode confinement, keeping low propagation losses and reaching single-transverse-mode operation.

The fabricated waveguides are promising for compact mode-locked oscillators at $\sim 1 \mu \mathrm{m}$ operating at high repetition rates (GHz-range).

\section{Declaration of competing interest}

The authors declare that they have no known competing financial interests or personal relationships that could have appeared to influence the work reported in this paper.

\section{Acknowledgements}

This work received funding from the Normandy Region, France (project CRISTO, CPER-LABEX EMC3). 

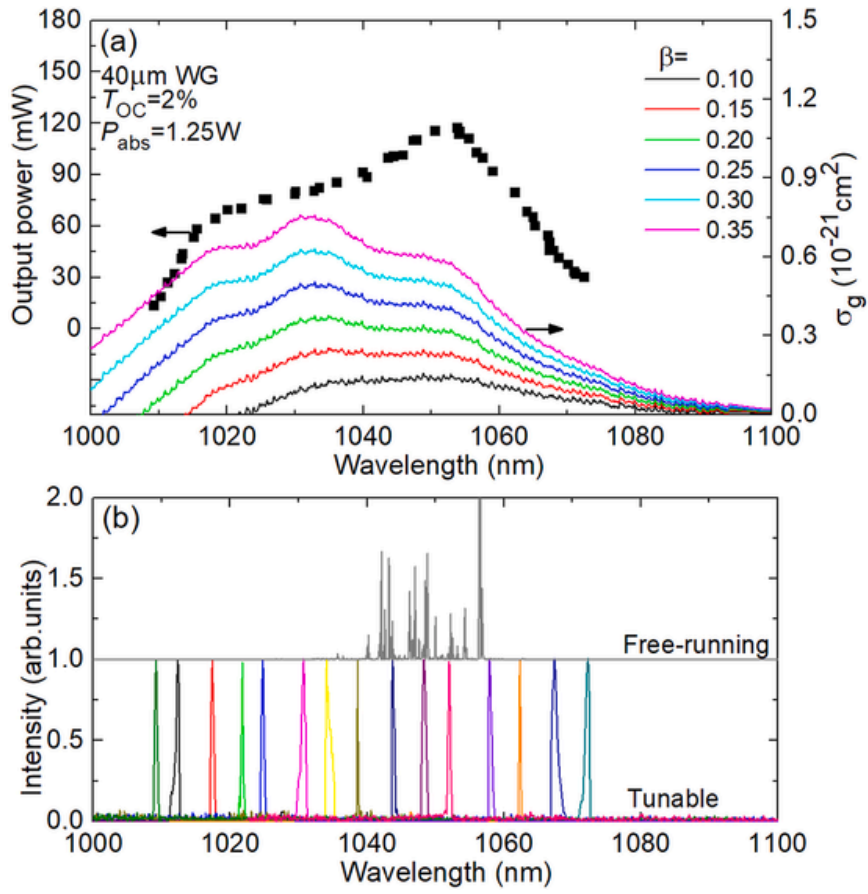

Fig. 14. Tunable deep-diced $\mathrm{Yb}^{3+}: \mathrm{CaF}_{2}$ ridge waveguide laser (WG width: $40 \mu \mathrm{m}$ ): (a) tunability curve, $T_{\mathrm{OC}}=2 \%, P_{\mathrm{abs}}=1.25 \mathrm{~W}$, gain cross-section, $\sigma_{\mathrm{g}}$, spectra for several inversion ratios $\beta=N_{2}\left({ }^{2} \mathrm{~F}_{5 / 2}\right) / N_{\mathrm{Yb}}$ are shown for comparison; (b) typical spectra of laser emission from the tunable laser; the spectrum for the free-running laser is shown for comparison.

Table 2

. Output characteristics* of $\mathrm{Yb}^{3+}: \mathrm{CaF}_{2}$ waveguide lasers reported so far.

\begin{tabular}{|c|c|c|c|c|c|c|c|c|c|}
\hline Method ** & $\mathrm{Yb}, \mathrm{at} . \%$ & $P_{\text {out }}, \mathrm{W}$ & $\eta, \%$ & $P_{\text {th }}, \mathrm{W}$ & $\lambda_{\mathrm{L}}, \mathrm{nm}$ & $\eta_{\mathrm{opt}}, \%$ & $\eta_{\text {coupl }}, \%$ & $\delta_{\text {loss }}, \mathrm{dB} / \mathrm{cm}$ & Ref \\
\hline ULI & 2.0 & 0.17 & $\sim 56$ & 0.074 & 1014,1028 & 44.3 & - & 0.5 & [25] \\
\hline LPE & 1.4 & 0.11 & 12.9 & 0.24 & 1037 & $\sim 6$ & 73 & $0.14 \pm 0.05$ & [28] \\
\hline \multirow[t]{2}{*}{ Dicing } & 4.5 & 0.72 & 76.0 & 0.165 & 1029-1051 & 38.9 & 74.2 & $0.13 \pm 0.05$ & $* * *$ \\
\hline & & 0.33 & 27.9 & 0.055 & 1038-1059 & 17.6 & & & \\
\hline
\end{tabular}

$P_{\text {out }}$ - output power, $\eta$ - slope efficiency vs. absorbed pump power, $P_{\text {th }}$ - laser threshold, $\lambda_{\mathrm{L}}-$ laser wavelength, $\eta_{\text {opt }}-$ optical-to-optical efficiency, $\eta_{\text {coupl }}-$ pump coupling efficiency. **Fabrication method: ULI - Ultrafast Laser Inscription, LPE - Liquid Phase Epitaxy.

$* * *$ This work. 


\section{References}

[1] N. Courjal, B. Guichardaz, G. Ulliac, J.Y. Rauch, B. Sadani, H.H. Lu, M.P. Bernal, High aspect ratio lithium niobate ridge waveguides fabricated by optical grade dicing, J. Phys. D Appl. Phys. 44 (2011) 305101.

[2] M.F. Volk, S. Suntsov, C.E. Rüter, D. Kip, Low loss ridge waveguides in lithium niobate thin films by optical grade diamond blade dicing, Optic Express 24 (2016) 1386-1391.

[3] L.G. Carpenter, S.A. Berry, C.B.E. Gawith, Ductile dicing of $\mathrm{LiNbO}_{3}$ ridge waveguide facets to achieve $0.29 \mathrm{~nm}$ surface roughness in single process step, Electron. Lett. 53 (2017) 1672-1674.

[4] N. Courjal, F. Devaux, A. Gerthoffer, C. Guyot, F. Henrot, A. Ndao, M.P. Bernal, Low-loss $\mathrm{LiNbO}_{3}$ tapered-ridge waveguides made by optical-grade dicing, Optic Express 23 (2015) 13983-13990.

[5] E. Kifle, P. Loiko, U. Griebner, V. Petrov, P. Camy, A. Braud, M. Aguiló, F. Díaz, X. Mateos, Diamond saw dicing of thulium channel waveguide lasers in monoclinic crystalline films, Opt. Lett. 44 (2019) 1596-1599.

[6] G.F. Chen, X. Zhao, Y. Sun, C. He, M.C. Tan, D.T. Tan, Low loss nanostructured polymers for chip-scale waveguide amplifiers, Sci. Rep. 7 (2017) 1-8 3366.

[7] J. Zhang, W.T. Guo, C.Y. Tang, S. Yan, W.N. Li, C.X. Liu, Planar and ridge waveguides in $\mathrm{Yb}^{3+}$-doped silicate glasses fabricated by proton implantation and precise diamond blade dicing, Optic Commun. 453 (2019) 124344.

[8] Y. Jia, C.E. Rüter, S. Akhmadaliev, S. Zhou, F. Chen, D. Kip, Ridge waveguide lasers in Nd:YAG crystals produced by combining swift heavy ion irradiation and precise diamond blade dicing, Opt. Mater. Express 3 (2013) 433-438.

[9] S.H. Waeselmann, C.E. Rüter, D. Kip, C. Kränkel, G. Huber, Nd:sapphire channel waveguide laser, Opt. Mater. Express 7 (2017) 2361-2367.

[10] P. Loiko, R. Soulard, G. Brasse, J.L. Doualan, B. Guichardaz, A. Braud, A. Tyazhev, A. Hideur, P. Camy, Watt-level Tm:LiYF 4 channel waveguide laser produced by diamond saw dicing, Optic Express 26 (2018) 24653-24662.

[11] D. Brüske, S. Suntsov, C.E. Rüter, D. Kip, Efficient ridge waveguide amplifiers and lasers in Er-doped lithium niobate by optical grade dicing and three-side Er and $\mathrm{Ti}$ in-diffusion, Optic Express 25 (2017) 29374-29379.

[12] R. Li, C. Pang, Z. Li, N. Dong, J. Wang, F. Ren, S. Akhmadaliev, S. Zhou, F. Chen, Monolithic waveguide laser mode-locked by embedded Ag nanoparticles operating at $1 \mu \mathrm{m}$, Nanophotonics 8 (2019) 859-868.

[13] S.N. Khonina, N.L. Kazanskiy, M.A. Butt, Evanescent field ratio enhancement of a modified ridge waveguide structure for methane gas sensing application, IEEE Sensors 20 (2020) 8469-8476.

[14] J. Charrier, M.L. Brandily, H. Lhermite, K. Michel, B. Bureau, F. Verger, V. Nazabal, Evanescent wave optical micro-sensor based on chalcogenide glass, Sensor. Actuator. B Chem. 173 (2012) 468-476.

[15] P. Loiko, L. Gauthier-Manuel, G. Brasse, E. Kifle, L. Guillemot, A. Braud, A. Benayad, V. Menard, P. Camy, Channel waveguide lasers in bulk Tm:LiYF 4 produced by deep diamond-saw dicing, Optic Express 28 (2020) 26676-26689.
[16] F. Druon, S. Ricaud, D.N. Papadopoulos, A. Pellegrina, P. Camy, J.L. Doualan, R. Moncorgé, A. Courjaud, E. Mottay, P. Georges, On $\mathrm{Yb}: \mathrm{CaF}_{2}$ and $\mathrm{Yb}: \mathrm{SrF}_{2}$ : review of spectroscopic and thermal properties and their impact on femtosecond and high power laser performance, Opt. Mater. Express 1 (2011) 489-502.

[17] G.A. Slack, Thermal conductivity of $\mathrm{CaF}_{2}, \mathrm{MnF}_{2}, \mathrm{CoF}_{2}$, and $\mathrm{ZnF}_{2}$ crystals, Phys. Rev. 122 (1961) 1451-1464.

[18] V. Petit, P. Camy, J.-L. Doualan, X. Portier, R. Moncorgé, Spectroscopy of $\mathrm{Yb}^{3+}: \mathrm{CaF}_{2}$ : from isolated centers to clusters, Phys. Rev. B 78 (2008) 1-12 085131.

[19] A. Lucca, M. Jacquemet, F. Druon, F. Balembois, P. Georges, P. Camy, J.L. Doualan, R. Moncorgé, High-power tunable diode-pumped $\mathrm{Yb}^{3+}: \mathrm{CaF}_{2}$ laser, Opt. Lett. 29 (2004) 1879-1881 2004)

[20] V. Petit, J.L. Doualan, P. Camy, V. Ménard, R. Moncorgé, CW and tunable laser operation of $\mathrm{Yb}^{3+}$ doped $\mathrm{CaF}_{2}$, Appl. Phys. B 78 (2004) 681-684.

[21] G. Machinet, P. Sevillano, F. Guichard, R. Dubrasquet, P. Camy, J.-L. Doualan, R. Moncorgé, P. Georges, F. Druon, D. Descamps, E. Cormier, High-brightness fiber laser-pumped 68 fs-2.3 W Kerr-lens mode-locked Yb:CaF 2 oscillator, Opt. Lett. 38 (2013) 4008-4010.

[22] S. Ricaud, F. Druon, D.N. Papadopoulos, P. Camy, J.-L. Doualan, R. Moncorgé, M. Delaigue, Y. Zaouter, A. Courjaud, P. Georges, E. Mottay, Short-pulse and high-repetition-rate diode-pumped $\mathrm{Yb}: \mathrm{CaF}_{2}$ regenerative amplifier, Opt. Lett. 35 (2010) 2415-2417.

[23] M. Siebold, M. Hornung, R. Boedefeld, S. Podleska, S. Klingebiel, C. Wandt, F. Krausz, S. Karsch, R. Uecker, A. Jochmann, J. Hein, M.C. Kaluza, Terawatt diode-pumped $\mathrm{Yb}: \mathrm{CaF}_{2}$ laser, Opt. Lett. 33 (2008) 2770-2772.

[24] V. Petit, P. Moretti, P. Camy, J.L. Doualan, R. Moncorgé, Active waveguides produced in $\mathrm{Yb}^{3+}: \mathrm{CaF}_{2}$ by $\mathrm{H}^{+}$implantation for laser applications, J. Alloys Compd. 451 (2008) 68-70.

[25] Y. Ren, C. Cheng, Y. Jia, Y. Jiao, D. Li, M.D. Mackenzie, A.K. Kar, F. Chen, Switchable single-dual-wavelength $\mathrm{Yb}, \mathrm{Na}: \mathrm{CaF}_{2}$ waveguide lasers operating in continuous-wave and pulsed regimes, Opt. Mater. Express 8 (2018) 1633-1641.

[26] E. Daran, R. Legros, P. Pernas, C. Fontaine, Er-Yb codoped $\mathrm{CaF}_{2}$ thin films grown by molecular beam epitaxy, J. Appl. Phys. 81 (1997) 679-684.

[27] A. Peña, P. Camy, A. Benayad, J.-L. Doualan, C. Maurel, M. Olivier, V. Nazabal, R. Moncorgé, $\mathrm{Yb}: \mathrm{CaF}_{2}$ grown by liquid phase epitaxy, Opt. Mater. 33 (2011) $1616-1620$.

[28] P. Loiko, R. Soulard, E. Kifle, L. Guillemot, G. Brasse, A. Benayad, J.-L. Doualan, A. Braud, M. Aguiló, F. Díaz, X. Mateos, P. Camy, Ytterbium calcium fluoride waveguide laser, Optic Express 27 (2019) 12647-12658.

[29] I.H. Malitson, A redetermination of some optical properties of calcium fluoride, Appl. Optic. 2 (1963) 1103-1107.

[30] J.A. Caird, S.A. Payne, P.R. Staber, A.J. Ramponi, L.L. Chase, W.F. Krupke, Quantum electronic properties of the $\mathrm{Na}_{3} \mathrm{Ga}_{2} \mathrm{Li}_{3} \mathrm{~F}_{12}: \mathrm{Cr}^{3+}$ laser, IEEE J. Quant. Electron. 24 (1988) 1077-1099.

[31] Lasers and Laser-Related Equipment - Test Methods for Laser Beam Widths, Divergence Angles and Beam Propagation Ratios - Part 1: Stigmatic and Simple Astigmatic Beams, 2005 ISO 11146-1.

[32] M. Schellhorn, High-power diode-pumped Tm: YLF laser, Appl. Phys. B 91 (2008) 71-74. 